\title{
HUACAS OLVIDADAS Y CERROS SANTOS. APUNTES METODOLÓGICOS SOBRE LA CARTOGRAFÍA SAGRADA EN LOS ANDES DEL SUR DE BOLIVIA
}

Pablo Cruz

A través de la articulación de fuentes coloniales tempranas con los registros arqueológicos y etnográficos locales, hemos identificado varios cerros sacralizados y huacas prehispánicas de la regiones de Potosí y Chuquisaca (Bolivia). A partir de tres casos: los cerros Potosí y Porco, el cerro Quiquijana y el cerro Poder de Dios, se exploran y analizan las dimensiones religiosas y políticas del culto a las montañas en los Andes surandinos.

Palabras claves: cerros - huacas - incas - conquista - ritual

Abstract

A combination of early colonial sources and local archaeological and ethnographic data enable this paper to identify the cases of mounts Potosí and Porco, Quiquijana, and Poder de Dios as pre-Columbian huacas and sacred mountains in the region of Potosí and Chuquisaca (Bolivia). Their study and analysis explores the religious and political dimensions of mountain cults in the South Central Andes.

Key words: mountains - huacas - Incas - conquest - ritual Recibido: noviembre 2008. Aceptado: julio 2009

1 Consejo Nacional de Investigaciones Científicas y Técnicas (CONICET). Parque Nacional Calilegua, Calilegua (4514), Jujuy, ARGENTINA. Email: pablocruzfr@yahoo.fr.

\section{- InTROducción}

Muchos investigadores han señalado los problemas que pueden surgir al articular las fuentes históricas con el registro arqueológico. Entre ellos Pärssinen (2005: 4), quien sostiene que de la comparación directa entre ambos tipos de datos pueden surgir resultados distorsionados. Según este autor, solo después de obtener resultados independientes en cada disciplina sería posible intentar una comparación y una síntesis. Los resultados de una disciplina pueden ser utilizados como hipótesis de otra, teniendo siempre en cuenta que el punto de vista del arqueólogo es muy distinto al del historiador. La sentencia de Pärssinen da lugar a varios comentarios. El primero, de corte epistemológico, es considerar que los problemas de esta relación conflictiva provienen del hecho de que se trata de fenómenos diferentes solo posibles de ser abordados por disciplinas o puntos de vistas específicos. Sin embargo, no es tanto la naturaleza del dato ni el enfoque de la disciplina lo que determina una realidad específica, sino más bien la posición del observador y su contexto en el proceso de construir conocimiento, es decir "el punto de vista", algo que es independiente de la disciplina.

En general las ciencias sociales carecen de un paradigma que permita realizar comparaciones mecánicas y sencillas, independientemente de si se trata de registros análogos o no. Lejos estamos de realizar comparaciones sociales con la sistematicidad de las ciencias duras y biológicas. De hecho, es en el tratamiento de la compleja naturaleza humana, de la subjetividad y de la incertidumbre, que las ciencias sociales encuentran su especificidad y su interés. En el caso de los estudios arqueoló- 
gicos abocados a períodos y sociedades protohistóricas e históricas, es importante reconocer la imposibilidad de disociar ambos registros. La data arqueológica no habla por sí misma, el objeto, las hipótesis, los objetivos de investigación y las interpretaciones se fundamentan en supuestos, conceptos y clasificaciones de la realidad que muchas veces se originan en las fuentes históricas.

No obstante, aunque rígidas y tajantes, las recomendaciones de Pärssinnen son válidas. Siempre es necesario guardar recaudos ante el problema de la intencionalidad de las fuentes, sobre todo cuando éstas se originaron en contextos de tensión social (incas, Conquista, Colonia). Como señala J. L. Martínez (2003), en todo análisis histórico resulta imperioso desglosar los diferentes estratos de significación que presentan las fuentes y analizarlos considerando su particular contexto de producción.

Los casos que trataremos muestran que si bien no es posible generalizar acerca de la relación entre los registros histórico y arqueológico, su articulación en un diálogo constante y dialéctico no solo es factible sino que permite abordar nuevos aspectos que hubieran sido imposibles de desarrollar desde un único registro. Para ello es necesario tener en cuenta que la ausencia del dato es tan significativa como el dato mismo, y que las causas de dicha ausencia pueden ser encontradas y explicadas tanto en términos históricos como arqueológicos.

\section{$\uparrow$ Cerros y Huacas. Apuntes metodológicos}

Varios cronistas de comienzos de la Colonia brindaron informaciones acerca del rol preponderante que tuvieron las montañas en la religiosidad de los pueblos andinos prehispánicos, particularmente entre sus principales interlocutores: los incas. ${ }^{2}$ Testimonios de la devoción de los incas hacia las altas cumbres, sobre todo aquellas con nieves eternas, se encuentran en las numerosas instalaciones rituales y santuarios de altura, muchos de los cuales estuvieron asociados con los ritos sacrificiales de la capacocha. ${ }^{3}$

\footnotetext{
2 Por ejemplo, Calancha (1978 [1638-1653]), Cieza de León (1988 [1553]), Guaman Poma de Ayala (1989 [1615]), Matienzo (1967 [1567]), Albornoz (1989 [1572]), Murúa (Ossio 2004), Ramos Gavilán (1976 [1621]).

3 Por ejemplo, Aconcagua, El Plomo, El Toro, Chuscha, Llullaillaco,
}

Sin embargo, tanto las fuentes como la arqueología nos señalan que otros cerros, no necesariamente tan majestuosos y con nieves eternas, formaban igualmente parte del paisaje religioso precolombino y fueron el escenario donde se desarrollaron intensas prácticas rituales. ${ }^{4} \mathrm{El}$ santuario inca del cerro Amarillo en la serranía oriental de Jujuy, el cerro Caltama en la región de Calcha en Potosí, y otros sobre los cuales nos referiremos más adelante, testimonian que la sacralización de un determinado cerro puede ser independiente de su majestuosidad, morfología y localización. Más bien, tal como lo sugieren Platt y Quisbert (2008), habría una fuerte relación entre los cerros sacralizados y la existencia en ellos de yacimientos de metal de plata y cobre. En este sentido, la hipótesis planteada por estos autores acerca de la existencia en tiempos del Inka de un sistema de ceques minerales que conducían hacia los cerros sagrados y huacas mineras constituye una interesante pista que investigar.

La articulación del registro histórico con la arqueología, la toponimia y la información oral nos permitió identificar varios cerros sacralizados de Potosí y Chuquisaca citados en las fuentes coloniales tempranas. Otros cerros, sobre los cuales no se poseen referencias históricas, fueron igualmente identificados siguiendo esta relación entre cerros y mineral, articulando en ello los registros arqueológicos y etnográficos. Dos razones explican porqué estas regiones son particularmente propicias para identificar antiguos cerros sacralizados (Figura 1). Por un lado, en ellas se concentran numerosos yacimientos de minerales metalíferos, particularmente en la cordillera de Los Frailes de Potosí; y por el otro, en conjunto, Potosí y Charcas conformaron uno de los centros neurálgicos del poder económico y político de la empresa colonial en los Andes, relacionado con la explotación de los fabulosos yacimientos de Potosí, dando origen a una abundante base documental e historiográfica. Gran parte de la infomación sobre la que se basa este trabajo tiene

Chañi, Quehuar, Acay, Licancabur, Illimani, Picchu Picchu (Reinhard 1983; Beorchia 1985; Ceruti 1999; Vitry 1999, entre otros).

4 Actualmente, la veneración de una montaña no implica necesariamente el desarrollo de prácticas rituales en la misma. De hecho, hemos podido constatar como algunos cerros de Bolivia considerados como apu mayores (p.e., Potosí, Tata Sabaya, Tunupa, Sajama, Illimani), son con frecuencia invocados y objeto de frecuentes challas por poblaciones bastante distanciadas geográficamente de los mismos. 


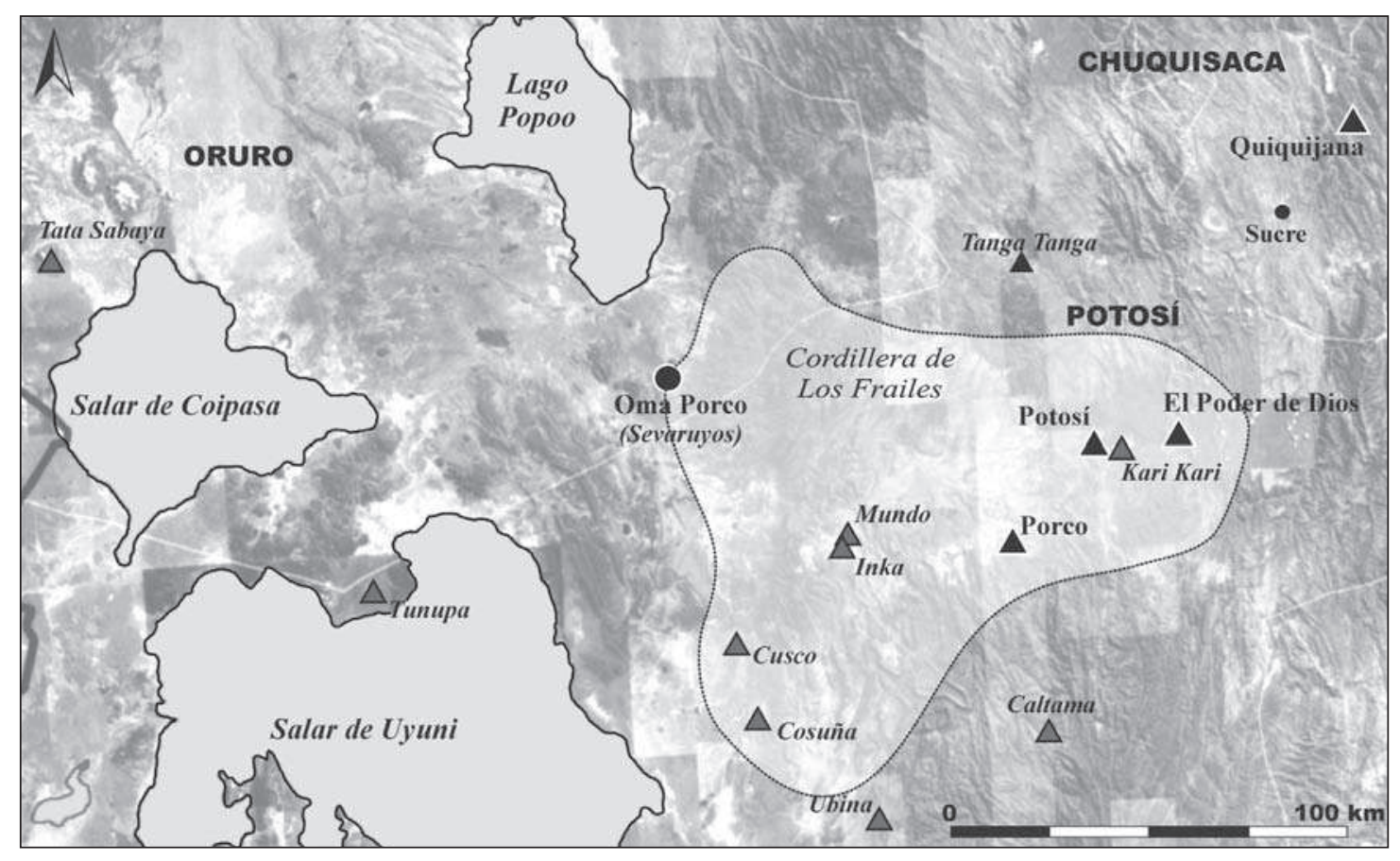

Figura 1. Mapa general de la región con localización de los sitios citados.

origen en los documentos y sus respectivos análisis, publicados por Platt y colaboradoras (2006).

Desde el punto de vista metodológico los casos estudiados muestran básicamente tres situaciones que, más allá de las particularidades regionales, pueden ser comunes en el resto del Área Andina: 1) cerros con registros históricos pero sin correlato arqueológico; 2) cerros con registros históricos y con un correlato arqueológico estricto, y 3 ) cerros con registros históricos y con correlato arqueológico y etnográfico. A estos casos se suman aquelos cerros sin referencias históricas, pero en los cuales se han identificado santuarios. Trataremos a continuación estos tres casos.

Sin embargo, antes es importante señalar que el término huaca fue utilizado antiguamente para identificar muchos de estos cerros sagrados, también, al mismo tiempo designó a las divinidades andinas, sus representaciones, los espacios rituales donde éstas se encontraban depositadas, como a los diversos niveles de sacralidad (Estenssoro 2003: 96). Es así que en su diccionario, Bertonio (1984 [1612]) traduce al castellano huaca como "...ídolo en forma de hombre, carnero, y los cerros que adoraban en su gentilidad...” y De Santo Tomás (1560, cit. en Estenssoro 2003: 96) lo hace como "... ydolo, templo de ydolos, o el mismo ydolo...".

\section{* Huacas calladas. Los cerros de} Potosí y Porco

Los importantes yacimientos de plata explotados en los cerros de Potosí y Porco desde tiempos prehispánicos (Cruz et al. 2005; Van Buren y Mills 2005; Cruz 2007), son dos ejemplos que ilustran los alcances y las dificultades que pueden existir a la hora de articular los registros históricos y arqueológicos. Aunque algunas fuentes identifican a ambos cerros como huacas y santuarios, la evidencia ceremonial solo pudo ser corroborada desde la arqueología en el caso del cerro de Porco. La explicación del silencio sobre la huaca de Potosí reside en diferentes factores relacionados con la evolución social del sitio, como también en algunos aspectos políticos que intervinieron en los primeros momentos de la Colonia y que condicionaron tanto los discursos recogidos por los cronistas como sus propios relatos. Veamos primero este caso. 
En la "Relación del cerro Rico de Potosí y su descubrimiento" De la Fuente Sanct Angel recoge el testimonio póstumo de Diego Guallpa, descubridor oficial de las vetas de plata, quien brinda referencias precisas sobre la huaca que se encontraba en la cumbre del cerro.

"Dijo más, que un día se juntaron cuatro soldados, que se decían Marcos Xaramonte, Alvaro de Olmedo, Gaspar Montesinos y Juan Camargo, a ver una loma de soroche questaba junto al cerro de Potosí, que hoy llamamos Asientos de Gonzalo Pizarro, en busca de minas y soroche, y le dijeron estando en la dicha loma: vee aquel cerro y en lo más alto dél hallarás much a plata labrada y oro ofrecido a la guaca que en él está'. Subió al cerro este dicho indio Guallpa en compañia de otro indio que le señalaron para que con él fuese, por ser la subida, mucha y áspera, distancia de más de dos mill pasos. Yendo por su jornada con dificultad, llegaron ambos indios a lo más alto del cerro de Potosí, el cual cerro tiene una mesa en lo más alto del despacio de cien pies, poco más o. menos, y en contorno igual por todas partes. Alli hallaron ser adoratorio de los indios comarcanos y haber algunas cosas ofrecidas de poca importancia a la guaca que alli estaba, lo cual todo cogió este dicho don Diego Guallpa, y lo cargó en su compañero y lo envió a los cuatro españoles que quedaban en los Asientos que dicen de Gonzalo Pizarro. Quedóse solo este indio Guallpa en el cerro de Potosí, después de haber enviado a su compañero con los despojos de la guaca questaba en lo más alto del cerro, a los cuatro cristianos que le habían enviado..." (1965 [1572]: 358-359; el subrayado es nuestro).5

Los más de 450 años de ininterrumpida explotación minera del cerro Rico borraron todo rastro del santuario que se localizaba en su cumbre. Sin embargo, la descripción ofrecida en el relato de Guallpa indica que éste poseía una plataforma cuadrangular de alrededor de $8.3 \mathrm{~m}$ de lado (30 pies), ${ }^{6}$ en la cual se encontraban depositadas algunas "ofrendas" dedicadas a la huaca en plata labrada, en oro y "cosas de poca importancia". Esta descripción, aunque somera, concuerda con la información que existe sobre varios santuarios de

5 Ver análisis de este documento en Platt y Quisbert (2008: 239-242).

6 Se utiliza como medida el "pie castellano" cuya equivalencia es $0.276 \mathrm{~m}$.

7 Se trata muy probablemente de miniaturas antropomorfas y zoomorfas acompañadas de ofrendas de tejidos y conchas de Spondylus sp. (mullu) frecuentemente halladas en los santuarios de altura incas. altura. No obstante, la fuente especifica que esta huaca habría sido adoratorio de "indios comarcanos" sin mencionar nada acerca de los incas. Esta omisión resulta extraña si tomamos en cuenta la pertenencia de Guallpa a la élite inca y el rol central que tuvo en el descubrimiento de las vetas de plata del cerro Rico (Platt y Quisbert 2008). Originario de la región de Yamqui, Diego Guallpa era hijo de Alcaxuxa, principal del ayllu de hanansaya en Chumbivilca, y de joven se desempeñó como guardián de las plumas del Inka Huascar (De la Fuente Sanct Angel 1965 [1572]: 358). Más allá de ello, otros elementos dejan ver la impronta del Tawantinsuyo en el cerro de Potosí. Los santuarios de altura erigidos por los incas formaban parte de una estrategia de conquista ritual (Nielsen y Walker 2000), y en muchos de ellos se desarrollaron los ritos sacrificiales de la capacocha (Duviols 1976). Estos santuarios cristalizaban en el paisaje, mediante el sacrificio de niños y jóvenes locales, una relación de alianza y sometimiento al Inka. Es probable también, que muchos de estos santuarios hayan sido emplazados en montañas sacralizadas antes de la llegada de los incas. Sabemos que éstos no solo se apropiaron y resignificaron muchos sitios de culto y huacas locales, sino que muchas veces los adoptaron e integraron dentro de su vida religiosa. Así, el cerro Rico de Potosí, llamado en tiempos preincaicos y en lengua puquina Capac Ique (Señor Rico), habría sido consagrado al sol por los incas en razón de sus riquezas minerales (Bouysse-Cassagne 2004). ${ }^{8}$ Esto concuerda con el hecho de que la mayoría de los santuarios de altura conocidos se localizan en regiones mineras, y muchas veces están asociados con instalaciones mineras ubicadas en los mismos cerros. En este sentido, es importante señalar que varias explotaciones mineras y sitios metalúrgicos con presencia de cerámica inca fueron registrados en el mismo cerro Rico de Potosí y en las colinas que lo circundan (Cruz 2007; Cruz y Absi 2008).

8 Es interesante constatar actualmente en numerosos mitos relacionados con los cerros del altiplano, que las montañas entregan sus riquezas a cambio del sacrificio de jóvenes. Muchos de estos mitos fueron recopilados como cuentos andinos de montaña por el CEPA (2003). Por otro lado, en varias regiones mineras de Potosí hemos escuchado sobre ofrendas de quínoa (cuyos granos simbolizan a las personas y sus almas) destinadas a las montañas y al "tío" de la mina, para que éstos entreguen su mineral.

$\mathrm{N}^{\circ} 38 / 2009$

ESTUDIOS ATACAMEÑOS

Arqueología y Antropología Surandinas 
En síntesis, a pesar de la no invisibilidad arqueológica, el testimonio de Diego Guallpa señala que en la cumbre del cerro Rico existió un santuario inca, una huaca adorada tanto por los incas como por los indios "comarcanos". La veneración en tiempos del Inka a la huaca del Capac Ique, más tarde llamado Potocchi, pone en evidencia la apropiación y resignificación de los cultos locales por parte de los incas en el contexto de la conquista territorial por parte del Tawantinsuyo.

Distinto es el caso del cerro y mina de Porco, donde según otro documento redactado por el cura Hernán González, se encontraba depositado la huaca homónima, que era venerada y objeto de peregrinación de todas las naciones que conformaban la federación qaraqara-charca (Espinoza 1969; Platt et al. 2006: 182-206).9 El cerro poseía grandes yacimientos de plata explotados por los incas; sus mejores vetas eran propiedad de Huayna Capac.

A diferencia del caso de Potosí, recientemente hemos hallado evidencias materiales de un santuario incaico en la cumbre del cerro de Porco. El santuario se compone de una gran plataforma longitudinal que delimita en su interior dos profundos pozos de ofrendas ${ }^{10}$, a lo menos cinco plataformas y varios conjuntos de recintos (Figuras 2 y 3 ). Sin embargo, sabemos que la huaca de Porco, ante la amenaza de su destrucción o saqueo, habría sido ocultada en otro cerro, el Caltama, de donde fue extirpada años más tarde por el mismo González (Platt et al. 2006). Este no fue un hecho aislado, por el contrario, varios documentos dan cuenta del ocultamiento de algunas huacas locales en el interior de los cerros -en ocasiones bajo un cerro arti-

\footnotetext{
9 Los peregrinajes continuaron incluso luego que la huaca de Porco fuera trasladada al cerro Caltama: "Pues acudían en romería a la dicha guaca desde Cochabamba y todo el distrito del Charcas, Cara[ca]ra Yampara y Chichas, y Yuras y Visisas y Asanaques y Asanaques y Carangas y Chuis, y quitándolo como lo quité cesó la adoración y idolatría, donde puse un humilladero..." (González de la Casa [1591] cit. en Platt et al. 2006: 187).

${ }^{10}$ Se trata de cavidades naturales que presentan galerías verticales, en un caso con una profundidad mayor a $40 \mathrm{~m}$. El acondicionamiento de estas galerías y la presencia de haldas (desmontes, la acumulación de roca y mena pobre en mineral situadas en las entradas de las minas) señalan actividades extractivas, probablemente vinculadas con la explotación minera (Téreygeol com. pers. 2009). Es importante señalar que la cumbre del cerro de Porco aún es un importante lugar de culto en el que se realizan actividades rituales vinculadas con la producción minera.
}

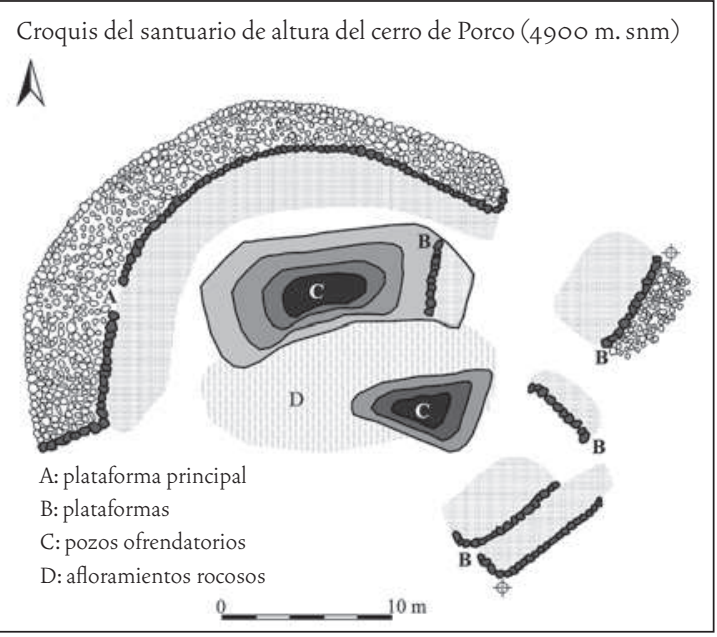

Figura 2. Croquis de planta del santuario del cerro de Porco.

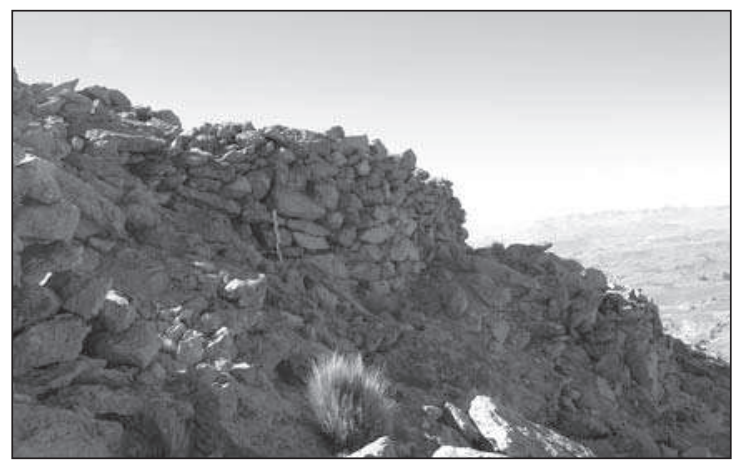

Figura 3. Detalle de los muros de dos plataformas del santuario del cerro de Porco.

ficial-, ante la amenaza de los españoles o, como pareciera ser el caso de Potosí, ante el riesgo de ser entregadas por miembros de la propia élite inca (Bouysse-Cassagne 2008). Por otro lado, resulta significativo ver como varias fuentes tempranas se empeñan en señalar que la mina de Porco fue trabajada en tiempos de los incas -y aún antes de ellos-, contrariamente, y en ocasiones, al mismo tiempo, asegurar el desconocimiento por parte de los indígenas de las vetas de plata del cerro Rico de Potosí. ${ }^{11}$ En gran medida, la construcción de Potosí como desierto humano antes de la llegada de los españoles es inversamente proporcional a la presentación de Porco como principal

\footnotetext{
${ }^{11}$ Entre ellos, Cieza de León (1988 [1553]: 239-241), De Benino (1965 [1573]: 354), Capoche (1959 [1585]), De Acosta (1979 [1550]:150).
} 
centro minero de la región. Recordemos que las investigaciones arqueológicas en Potosí pusieron en evidencia varias explotaciones mineras e instalaciones metalúrgicas asociadas con materiales incas. Estos sitios no se encuentran aislados, y a diferencia de lo sucedido en Porco, se insertan dentro de un territorio colonizado por los incas, quienes se establecieron tanto en las aglomeraciones locales como en asentamientos propios. La impronta del Tawantinsuyo en Potosí también está presente en el centro administrativo de Kayuna Pampa, en el taller alfarero de Jesús Valle bajo, en el paso del Qhapaqñan, y en numerosas colonias de mitmaqkuna (Cruz 2007; Cruz y Absi 2008). Los múltiples contrastes entre los cerros de Porco y Potosí sugieren que las referencias documentales sobre el santuario y huaca de Porco intervinieron en cierta medida para desviar la atención del cerro de Potosí, en un primer momento ante la amenaza de que los españoles se apropiasen de la huaca y de las vetas de plata, y más tarde en la legitimación de la apropiación española de éstas, acompañando la aseveración de que Potosí era un desierto humano (Cruz 2007). No obstante, transgrediendo un secreto al parecer conocido por todos, Murúa (Ossio 2004) deja explícito en un dibujo la relación del cerro de Potosí con la figura del Inka, quien habría participado de alguna manera en la entrega de las vetas junto a Diego Guallpa (Figura 4).

Es relevante también que el nombre de Porco además de identificar al centro minero y santuario aparece, en tanto que huaca asociado con el rayo y la guerra, a lo menos en otros dos cerros de Potosí: Caltama y Poder de Dios, así como en el centro administrativo y ceremonial inca de Oma Porco en Sevarullos, Aullagas (Raffino 1993). Más que a un centro minero específico, el nombre "Porco" parece referirse a la jurisdicción territorial de la huaca, la cual se corresponde con la cordillera de Los Frailes, y que aparte de los cerros de Porco y Potosí, alberga otros cerros minerales que fueron sacralizados por los incas tales como Ubina, Cosuña, Cusco, Inca, Mundo y Kari Kari. ${ }^{12}$ El centro administrativo y ceremonial de Oma Porco, tal como su nombre lo indica, debió haber ocupado un lugar central en la jurisdicción territorial de la huaca del mismo

${ }^{12}$ Además de los cerros Cuycoma, Chapoti, Suricaba y Aricaba relacionados por Hernán González con Porco (Platt et al. 2006: 184). El cerro Cuycoma, llamado después Cuscoma, puede corresponder al cerro Cusco.

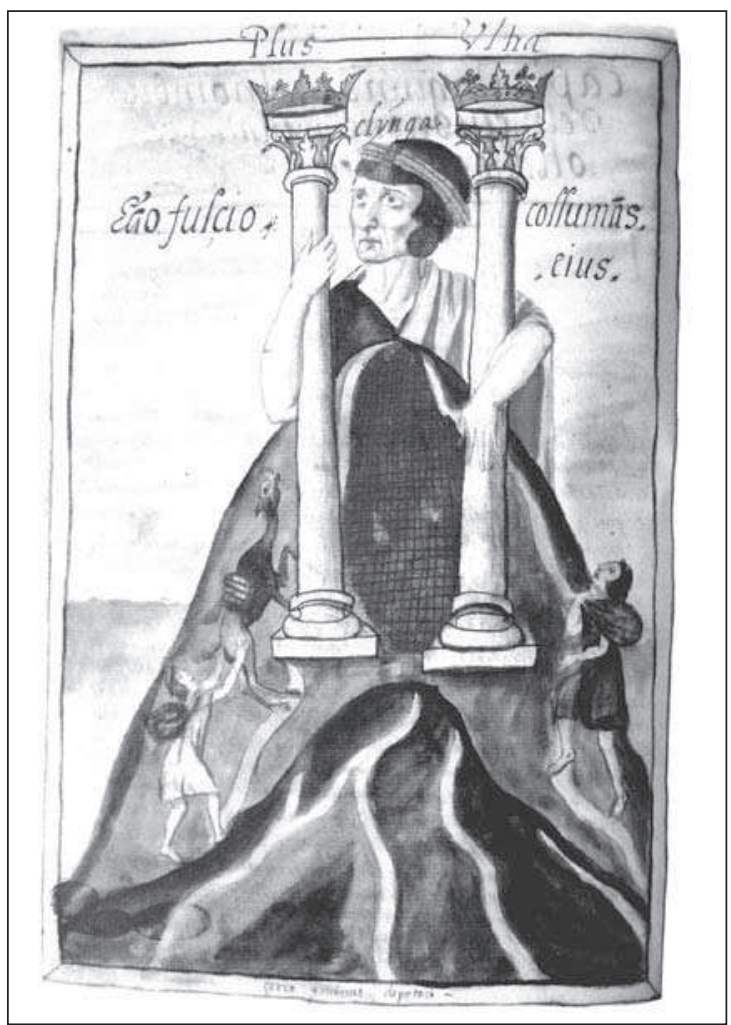

Figura 4. El Inka y el cerro de Potosí según Murúa (Ossio 2004).

nombre. Significativamente, las puertas de acceso de su imponente kallanka se abren hacia los principales cerros de la cordillera de Los Frailes (Figuras 5 y 6). Más tarde, con la llegada de los españoles, el dominio territorial de la huaca de Porco se convirtió en una jurisdicción administrativa del nuevo orden colonial. En este sentido, es probable que al situarse dentro de la jurisdicción territorial de la huaca de Porco, el cerro Rico de Potosí se haya encontrado directamente relacionado con esta divinidad. Algunas informaciones en la historia oral y en las fuentes escritas acompañan esta idea. Por un lado, en el mito que narra la llegada del Inka Huayna Capac a Potosí, la montaña de plata se le anuncia a éste mediante un gran estruendo de la tierra, evento desde el cual se deriva el nombre de Potocchi ("el que revienta"), un sonido semejante al trueno celestial, una de las manifestaciones de la divinidad de Porco (Platt et al. 2006: 167-174). A la inversa, según deja ver Pedro de Valdivia (1960 [1550]: 28), el nombre Rico atribuido al cerro de Potosí, parece haber sido utilizado para designar otros cerros con importantes 


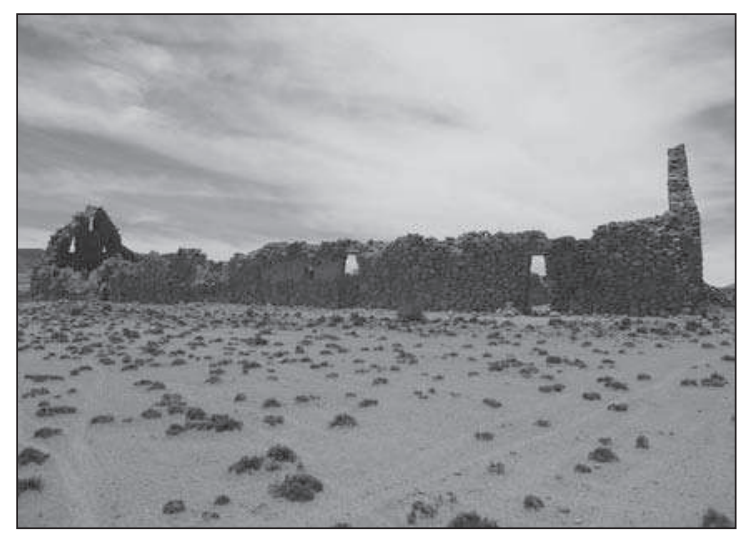

Figura 5. Oma Porco, kallanka del centro administrativo de Sevaruyos.

yacimientos de metales, entre ellos el cerro de Porco, de la misma manera que todos ellos también fueron llamados "Gran Señor". Otra coincidencia entre los cerros de Porco y Potosí se encuentra precisamente relacionada con la figura del Inka Huayna Capac. Según la visita que realizara Bartolomé Talaverano en 1538 (Bouysse-Cassagne 2008: 306) Guaynacaba (Huayna Capac) tuvo en su dominio las mejores vetas del cerro de Porco. Aunque el mito cuenta que la montaña de Potosí se negó a entregarle sus riquezas, adosado al cerro Rico se encuentran el cerro Guaynacabra (Guaynacaba), sobre el cual varias fuentes señalan que contenía ricos yacimientos de soroche (galena argentífera) y plata, y que fue escenario de dos eventos muy significativos. Primero, el lugar donde Gonzalo Pizarro, enemigo de Manco Inka, realizó las primeras explotaciones mineras españolas varios años antes del descubrimiento oficial del cerro Rico, construyendo instalaciones con muros tan altos que todavía tres décadas más tarde se veían desde la cumbre del cerro Rico (De Benino 1965 [1573]). Y es también desde los asientos de Pizarro en el cerro Guaynacabra que en 1545 Diego Guallpa, acompañado de cuatro españoles contrarios al encomendero, asciende a la cumbre del cerro Rico con la intención de condenar a la huaca de Potosí para después entregar sus vetas de plata. De suerte que la condena del santuario marcó al mismo tiempo un nuevo hito en las pugnas de poder y control territorial que enfrentaba a diferentes grupos de españoles. ${ }^{13}$

\footnotetext{
${ }^{13}$ Significativamente, el descubrimiento oficial del cerro Rico de Potosí tiene lugar inmediatamente después de que Gonzalo Pizarro partiera a Perú a enfrentarse con la Corona defendiendo los
}

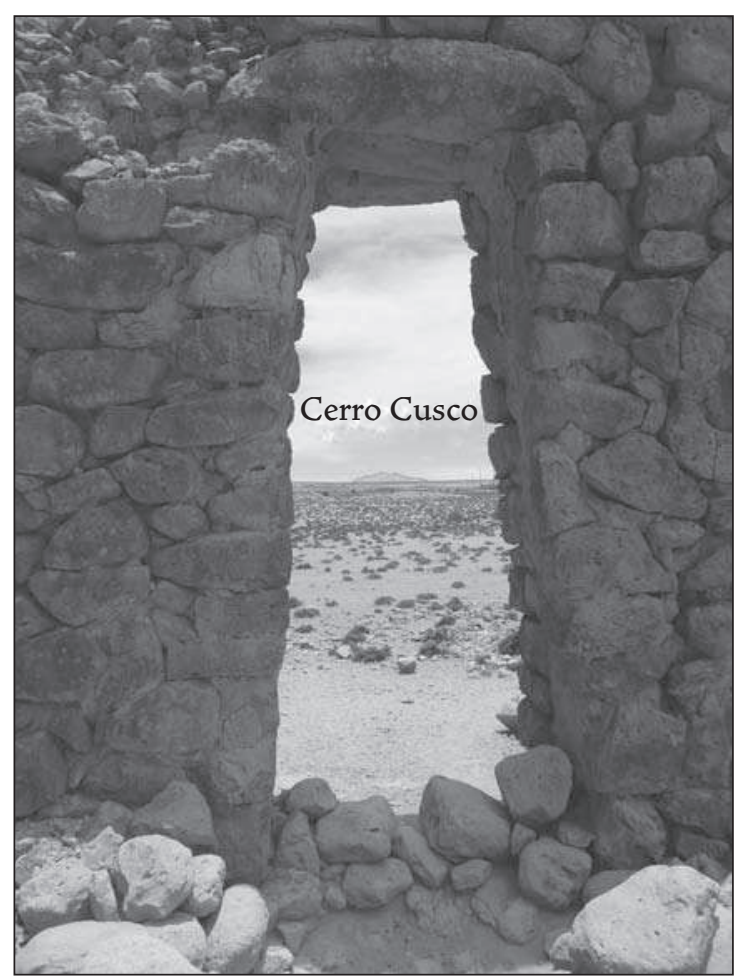

Figura 6. Vista del cerro Cusco desde una puerta de la kallanka de Sevaruyos.

Las prospecciones arqueológicas en el cerro Guaynacabra confirmaron la existencia de antiguas minas de soroche, un vasto sitio metalúrgico con cerámica inca y que utilizaba hornos de viento (huayrachina), y otro sitio metalúrgico con material cultural del período de contacto que correspondería al "asiento" de Gonzalo Pizarro mencionado en las fuentes escritas. Finalmente, encontramos una interesante pista nuevamente en un dibu-

intereses de los encomenderos. Desconociendo la jurisdicción de la encomienda de Pizarro, los españoles de Porco, leales al rey y cercanos a los incas con quienes establecieron algunas alianzas en torno a la producción de plata (Cruz 2007; Cruz y Absi 2008), se apropiaron de las vetas del cerro Rico. En un episodio narrado por Arzáns de Orzúa y Vela (1965 [1737]), pocos días después del descubrimiento oficial, los españoles se enfrentan en batalla con los indios comarcanos, liderados por Chaqui Catari, quienes tenían algún tipo de alianza con Gonzalo Pizarro contra los incas. Tal batalla ocurrió en la Cuesta de Jesús Valle, precisamente en el lugar donde las excavaciones arqueológicas revelaron la existencia de una instalación administrativa y taller cerámico inca (Cruz 2007). Como condición para el cese de los enfrentamientos, Chaqui Catari solicitó - sin éxito- el alejamiento de los españoles y que éstos le entregaran la cabeza del "traidor" Diego Guallpa. 


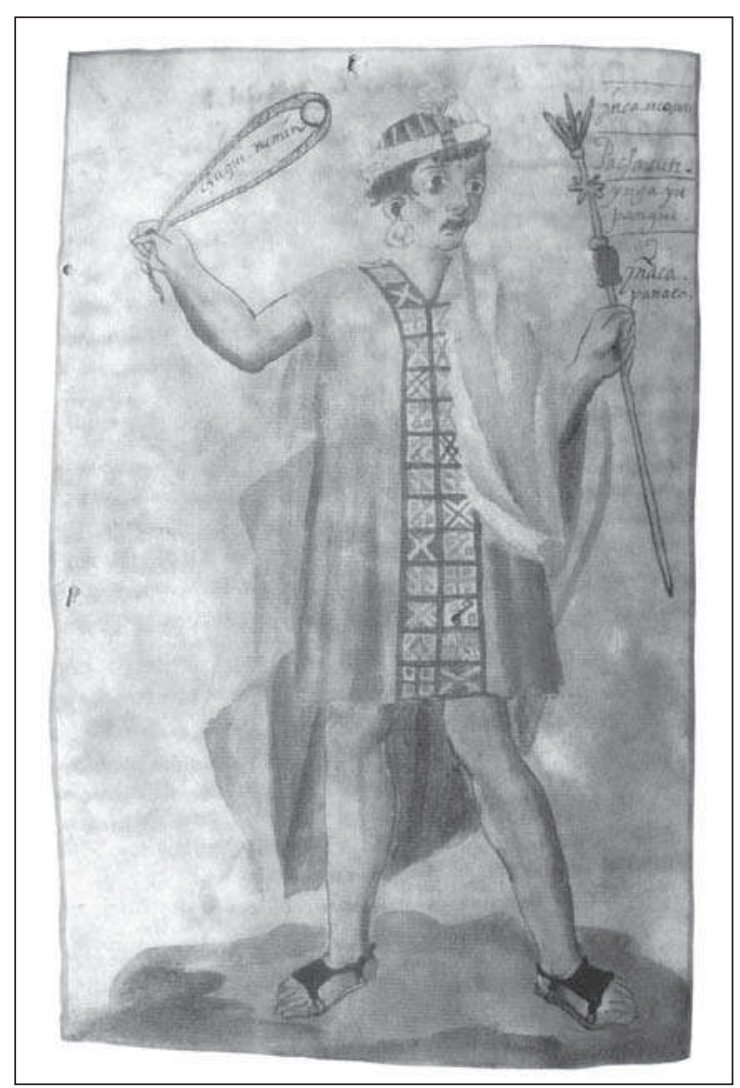

Figura 7. Pachacuti Yupanqui Inka según Murúa (Ossio 2004).

jo de Murúa (Ossio 2004), el cual representa al Inka Pachacuti Yupanqui (Figura 7). Aquí, como en Guaman Poma, el Inka es representando en movimiento maniobrando una huaraca con un proyectil esférico que lleva el nombre de chuquirumin. Este puede ser traducido como piedra del rayo (rumi: piedra), en tanto que chuqui se relaciona directamente con Chuqui Illa y Chuqui Illapa, denominaciones dadas al rayo, y uno de los nombres de la identidad tripartita de la huaca de Porco. La imagen de Pachacuti Inka, blandiendo su huaraca para lanzar la piedra del rayo - que es el rayo mismo-, es análoga a la representación de la divinidad andina Illapa (el rayo).14 Significativamente, tal como lo prueba un fechado por AMS realizado sobre una muestra de carbón de un recinto habitacional del centro administrativo de Kayuna Pampa (425 \$30 años AP; 1425-1512 cal. DC), la incorporación de la región de Potosí al Tawantinsuyo tuvo lugar precisamente con Pachacuti Inka.

14 Ver por ejemplo, Celestino (1997).
La condena de la huaca de Potosí y la intensificación de la producción minera marcaron una nueva etapa en el devenir de la montaña sagrada. Lejos de perder su trascendencia, el Señor Rico de Potosí mantuvo su lugar como hito extraordinario en la cartografía sagrada de la región, incluso fusionándose en la iconografía colonial con la Virgen. Desde entonces, las numerosas transformaciones y encuentros sociales y culturales fueron borrando paulatinamente la memoria de los antiguos cultos a la huaca de Potosí. Convertido finalmente en uno de los principales apu de la región, campesinos de regiones alejadas de Potosí, continúan hoy levantando sus vasos y pronunciando el nombre del cerro Rico durante sus rituales y fiestas religiosas.

\section{* Apoquiquixana y la replicación de las Huacas}

El cerro Quiquijana, localizado en los valles mesotérmicos de Chuquisaca, al norte de Sucre (ver Figura 1), muestra una correlación más precisa de los registros históricos y arqueológicos, y nos brinda otras interesantes pistas sobre los antiguos cultos a los cerros y huacas prehispánicas.

En su "Crónica moralizada", Calancha (1978 [16381653]) presenta al cerro Quiquijana (Apoquiquixana) como el más importante dentro de un conjunto de cerros minerales y sagrados que rodean la ciudad de Sucre ${ }^{15}$ (Figura 8), a los cuales se suma el cerro Choroquella donde había “...un gran santuario Gentílico, de cuyas ofrendas se izo un copioso tesoro, que muchos an buscado con diversas noticias...".

"Síguele Apoquiquixana, que es lo mismo que el gran señor Quiquixana, cerro por quien los Ingas i Pallas en el Cuzco, i en Chuquisaca asta oy se lamentan, diciendo, que después que les falta Quiquixana, no tienen plata ni oro...

En el cerro llamado Quiquixana se alló estos años un altar en que se sacrificava a un Idolillo de plata en forma de carnerillo pequeño, a quien le ofrecían los olocaustos que en este su altar se le

\footnotetext{
${ }^{15}$ Como los cerros Piquisa, Malmisa, Maragua, Aquillane, Chabaoro, Capactini, Sotane, Choquechambi, Uliuli, Quichane y Coyacamane: “...los más destos cerros tienen adoratorios que se hallan en ruinas antiguas con ídolos de piedra, cobre, plata i oro, con formas de diversas figuras..." Calancha (1978 [1638-1653]:302).
} 


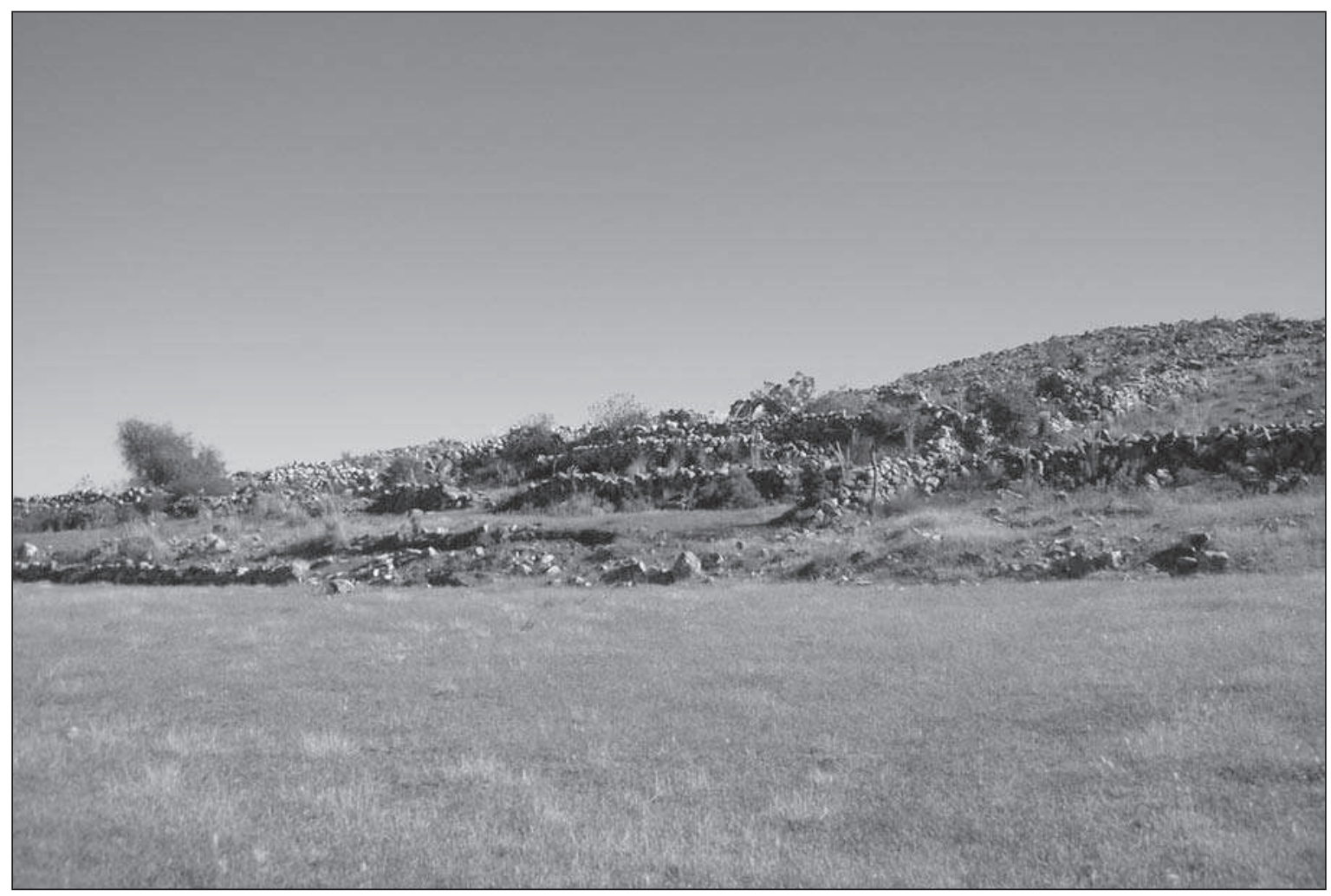

Figura 9. Conjunto de estructuras sobre sector ceremonial del Cerro Quiquijana.

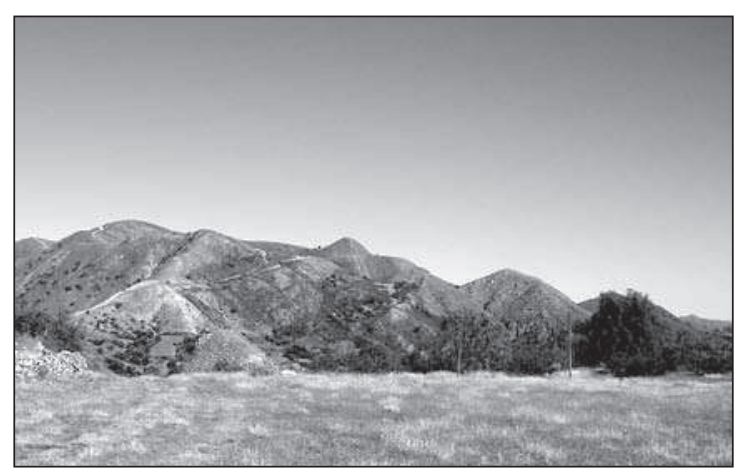

Figura 8. Vista de la cumbre del cerro Quiquijana desde una plaza ceremonial.

quemavan, i las cenizas i guesos quemados se allaron entre unas peñas, buscando los tesoros de la ofrenda, que no se an allado..." (Calancha 1978 [1638-1653]:301-302)

Siguiendo al pie de la letra este texto, localizamos sobre la parte superior del cerro un santuario prehispánico con a lo menos tres sectores principales. Un sector inferior, localizado en el faldeo norte, donde hay una plaza central rodeada por numerosos recintos y construcciones aterrazadas (Figura 9). Un segundo sector, localizado sobre este mismo faldeo cerca de la cumbre principal, presenta varios conjuntos de recintos habitacionales alineados. Un tercer sector, se emplaza sobre una de las cumbres menores del cerro, y se compone de varios recintos y un conjunto de grandes plataformas. De manera general, los estilos cerámicos locales conocidos como Yampara y Presto Puno son los más representados en la superficie, algunos muestran algunas diferencias distribucionales: cerámica rústica en el sector con plataformas y una mayor concentración de cerámica polícroma fina en sectores con recintos habitacionales. No se registró cerámica inca o altiplánica en la superficie.

En este caso, la descripción de Calancha señala la presencia del Tawantinsuyo a través del propio nombre del cerro, Apoquiquixana, que reproduce el nombre de un importante cerro-huaca de la región de Cusco ("que es lo mismo"), como en la referencia de que en este santuario 
se adoraba a un "idolillo de plata en forma de carnerillo pequeño", algo que coincide con las conocidas miniaturas con formas de llama que fueron halladas en numerosos santuarios incas de altura. Sin embargo, y a pesar de que el santuario posee varias plataformas en la cumbre, las características del sitio difieren de lo que se conoce hasta ahora sobre los santuarios de altura incaicos. Sin tener la intención de comparar este tipo de sitios desde una escala jerárquica dentro de la religiosidad andina prehispánica, el santuario del Quiquijana es considerablemente más grande y complejo que la mayoría de los santuarios de altura conocidos, acercándose más a la figura del centro ceremonial. ${ }^{16}$ No obstante, tampoco es un sitio comparable a los grandes centros ceremoniales incas de los Andes Centrales, como por ejemplo, Pachacamac, Machu Picchu o Choquequirao.

A diferencia de lo que sucede con el cerro Rico de Potosí, aquí, Calancha (1978 [1638-1653]) asocia el santuario del Quiquijana directamente con los incas y con la cartografía sagrada de Cusco. Sin embargo, la arqueología indica que se trata de un centro ceremonial preinca. Tanto la morfología de las construcciones como los estilos cerámicos observados en el sitio se ajustan a las tradiciones Yampara y Yampara Presto Puno, manifestaciones locales del período de Desarrollos Regionales. Esta relación posee una gran relevancia ya que evidencia la apropiación por parte de los incas de un sitio de culto local, y su resignificación mediante el otorgamiento del nombre de un apu de Cusco. Estamos lejos aún de comprender las razones por las cuales el cerro de Chuquisaca fue rebautizado con el nombre de Quiquijana, pero resulta interesante que Calancha lo presente como el santuario más importante de un grupo de 12 cerros con santuarios que rodean la ciudad de Sucre, lo cual sugiere (como en el caso de Porco-Potosí) la existencia de una jurisdicción territorial centralizada en una huaca principal. $\mathrm{Al}$ no existir referencias sobre este tipo de ordenamiento territorial antes de la llegada de los incas, es probable que éste haya surgido como parte de las estrategias de conquista ritual implementadas por el Tawantinsuyo. Pero el cerro de Chuquisaca no es la única réplica del Gran Señor

${ }^{16}$ Otros santuarios de altura localizados más al sur, como el del Licancabur, la Ciudacita o Nevados del Aconquija, se caracterizan igualmente por sus grandes dimensiones y complejidad de espacios y estructuras (A. Nielsen, com. pers. 2008).
Quiquixana. Cieza (1988 [1553]) señala la existencia de otro cerro llamado Quiquijana en la región de Apolo, al norte del departamento de La Paz, asociado a una serie de instalaciones y centros ceremoniales incas. ${ }^{17}$ Aunque no se dispone de elementos suficientes para entender las relaciones entre estos tres cerros que comparte el nombre, es posible que su replicación tenga que ver con los flujos territoriales y políticos de las panacas incas y sus huacas tutelares $y / o$ sus aliados, y sus relaciones de fuerza con las poblaciones y divinidades locales. En este sentido, no parece ser algo fortuito el que estos tres cerros se encuentren situados en zonas de valle y piedemonte.

\section{* Poder de Dios}

Como último caso, trataremos el cerro-huaca, llamado Poder de Dios, localizado a pocos kilometros de Potosí, en el vecino valle de Chaquí (ver Figura 1).

En una Petición de 1626, transcrita y analizada por Platt y colaboradoras (2006:215-220), dos españoles, Pedro de Sarabia y Juan de los Reyes, solicitan los reconocimientos y la colaboración del Estado colonial ante el descubrimiento de una fabulosa mina en Chaquí. El documento señala que a dos leguas del pueblo de ese nombre, en un cerro cercano al pueblo antiguo de Pacaxa, existía un cerro que llamaron "Poder de Dios" que guardaba en su interior dos inmensas vetas de plata. Pero además, en este cerro habrían sido ocultadas varias importantes huacas de la región, entre ellas, la de Porco. Para salvar las vetas y las huacas de la codicia española, los indígenas habrían cubierto su entrada bajo un cerro artificial. Transcribimos a continuación parte de esta Petición:

Manifestaciones de Minas ante el Alcalde Mayor:

"...la cual dicha mina está en un cerro frontero de la puerta de la iglesia de un pueblo viejo que llaman Pacaxa, que al presente por la banda del norte está una lagunilla como la media plaza principal de Potosí, y encima de la boca está una piedra al nacimiento del sol, muy grande y chata, echada, que mira a la puerta de dicha iglesia, y a un lado está una piedra hacia la parte de la laguna que la partió un rayo, y dicha piedra de la mina y la del rayo está con otra grande en triángulo... dicha

${ }^{17}$ Agradezco a I. Daillant por esta información. 
mina ponemos por nombre la limpia Concepción de Nuestra Señora, y a el dicho cerro ponemos por nombre el Cerro Poder de Dios..." (Platt et al. 2006:217).

Manifestación de huaca:

"...que hemos tenido noticias que en este dicho cerro del Poder de Dios y otro que está junto a él hay una huaca en que los indios metieron y tienen oculta mucha cantidad de plata, oro y otros metalesy riqueza, la cual dicha huaca manifestamos para la descubriry abrir y labrar por decir que está muchos estados debajo de tierra... entre tanto que ratificamos y hacemos nuevo registro ante ellos, y provee lo que más convenga a la real hacienda, y ponemos por nombre luego a la dicha huaca Santa Bárbara..." (Platt et al. 2006: 219).

\section{Petición:}

“...y en lo labrado de las dichas vetas y minas, en que entraban a labrar por dos bocas que tenían que están tan cerradas y tapadas, pusieron en un hueco de las dichas minas mucha cantidad de plata, oro y otras cosas, y un altar con ídolos donde tenían sus idolatrías, todo lo cual para tenerlo más oculto lo mudaron de otras huaca de Porco y otras partes, e hicieron principal huaca la dicha mina y huaca de ella..." (Platt et al. 2006: 219-220).

El detalle de las informaciones geográficas y la importancia de los datos contenidos en este documento (un cerro donde se habrían escondido ricas vetas de plata y varias huacas regionales muy cerca de Potosí), motivó una pequeña investigación para evaluar la correspondencia entre esta fuente documental y el registro arqueológico, pero también explorar la evolución social de un supuesto lugar de culto prehispánico asociado a los cerros. Para ello nos guiamos por la hipótesis de que si este cerro contenía una importante mina de plata y fue el lugar elegido para ocultar varias huacas regionales, es porque el cerro mismo estaba sacralizado. De ser así, probablemente existirían en la región rastros materiales y memoria sobre los antiguos cultos desarrollados en él. Algunas comparaciones reforzaban las variables y daban coherencia a la hipótesis. Por un lado, muchos cerros mineralizados fueron al mismo tiempo importantes lugares de culto y santuarios en tiempos prehispánicos; los cerros de Potosí y Porco son ejemplo de ello. En este sentido, es de hacer notar que los dos emprendedores mineros mencionados identifican como huaca al cerro Poder de Dios, y al cerro vecino, además de las huacas que fueron ocultadas en su interior. Por otro lado, tal como lo describe Álvarez (1998
[1588] cit. en Platt et al. 2006) el ocultamiento de huacas y divinidades en cuevas y cerros artificiales con el fin de preservarlos, parece haber sido una práctica generalizada en los primeros años de la Colonia. De hecho, este mismo autor menciona que no solo fueron ocultadas divinidades e ídolos sino también ancestros momificados.

Es interesante también el hecho de que los españoles hayan bautizado el cerro de Chaquí con el sugestivo nombre de Poder de Dios. Esto vuelve a señalar la jerarquía del cerro dentro de la geografía sagrada de Potosí a comienzos del siglo XVII. En efecto, no es un dato menor que en este cerro haya sido ocultada la huaca de Porco, una de las principales de la región, asociada al rayo y a la guerra (Bouysse-Cassagne 1993; Platt et al. 2006:165-174).

En la cartografía actual no existe para la región de Chaquí ningún cerro llamado Poder de Dios, tampoco un poblado antiguo en los márgenes de una pequeña laguna tal como lo señala la Petición de 1626. En cambio, sí existen dos comunidades llamadas Pacaja: Alta y Baja, que podrían corresponder al antiguo pueblo de Pacaxa citado en el documento. Este nombre sugiere que se trataría de una colonia de mitmaqkuna originaria de la región de Pakasa relacionada con la ocupación inca de Potosí. La existencia en Chaquí de dos comunidades llamadas Pacaja, que podría responder al antiguo ordenamiento dual de los ayllu de la región, nos llevó a dimensionar las distancias entre éstas y el pueblo, según el documento, a dos leguas de distancia (unos $10 \mathrm{~km}$ ). Para ello fue necesario localizar el pueblo histórico de Chaquí y la ruta que lo comunicaba con Potosí. En tiempos de las reformas toledanas fue creada la reducción de Xarandilla (Platt et al. 2006:378; A.M. Presta com. pers. 2007) que corresponde a la actual capital provincial: Santiago de Chaquí. Esto parece confirmarse en el trazado del pueblo, cuyo damero central está ordenado en calles que aún llevan el nombre de las comunidades periféricas según se acostumbraba en la época. También, en varios sectores del pueblo se registraron densas concentraciones de cerámica inca, altiplánica y colonial, dando cuenta de su prolongada ocupación. Si consideramos que alrededor de 50 años después de su creación, Xarandilla continuaba conservando su nombre, es posible que el antiguo poblado de Chaquí citado en las fuentes de fines del siglo XVI y del XVII corresponda al actual Chaquí Baños, lugar de aguas termales donde Gonzalo

$\mathrm{N}^{\circ} 38 / 2009$

EstUdios ATACAMEÑOS

Arqueología y Antropología Surandinas 
Pizarro tuvo su hacienda. Sin embargo, en los documentos coloniales consultados hay muy pocas referencias sobre la reducción de Xarandilla en comparación con el pueblo de Chaquí. Teniendo en cuenta la escasa distancia que separa el pueblo de Santiago de Chaquí y Chaquí Baños (unos $5 \mathrm{~km}$ en línea recta), y la densidad de la ocupación humana (favorecida por varios cursos de agua permanentes), es posible que las fuentes hayan considerado como pueblo de Chaquí a toda la zona, sin distinguir la reducción de su periferia. No obstante, el documento señala que el antiguo pueblo de Pacaxa se situaba dos leguas "más adelante" de Chaquí; es decir esa distancia (por el camino) antes de llegar al viejo poblado. Solo en el caso de Chaquí Baños las dos leguas desembocan en el territorio de una de las mencionadas comunidades pacajas (Alta). ${ }^{18}$ Cabe señalar además, que Chaquí Baños se encuentra cerca del sitio arqueológico Saca Saca, una de las principales aglomeraciones tardías de la región, y la zona más intensamente ocupada desde tiempos prehispánicos (Cruz 2007; Cruz y Absi 2008).

Otros elementos sugieren que el antiguo poblado de Pacaxa citado en el documento corresponde al territorio de la comunidad de Pacaja Alta, ya que en Pacaja Baja no existen cerros minerales, ni lagunas como lo señala la fuente. Se trata también de un conjunto habitacional mucho más reducido que Pacaja Alta y alejado de los principales caminos. Contrariamente, Pacaja Alta -cuyo territorio alberga la capital de Santiago de Chaquí (Xarandilla)-, se localiza al pie de los primeros faldeos de la cadena del Kari Kari (ver Figura 1), una región de fuerte tradición minera y con varias lagunas pequeñas. También es importante resaltar que al sureste, Pacaja Alta limita con la comunidad de Lupaqa, toponimia que confirma la existencia de antiguas colonias de mitmaqkuna traídas a la región en tiempos de los incas. En cuanto al camino colonial que unía Potosí con la región de Chaquí, según se observa en algunos tramos, parece haber seguido un trayecto que ingresaba en el valle de Chaquí bordeando el faldeo norte del Kari Kari y atravezando la comunidad de Pacaja Alta.

Por otro lado, en el centro de la comunidad de Pacaja

18 La distancia entre Chaquí Baños y Pacaja Alta es en línea recta de aproximadamente $5.15 \mathrm{~km}$, y por tierra entre 7.5 y $8.5 \mathrm{~km}$.
Alta, distante $2 \mathrm{~km}$ aproximadamente al noroeste de Santiago de Chaquí, existe hoy una pequeña capilla, al lado de la cual hay numerosas piedras "partidas por el rayo". Nuevamente encontramos una relación con la descripción presente en el documento colonial. Otras piedras partidas por el rayo se encuentran diseminadas a lo largo de los senderos que enlazan el territorio de la comunidad. Los comuneros de Pacaja Alta no reconocen la existencia de ningún pueblo antiguo; pero sí numerosas viviendas coloniales desperdigadas en todo su territorio que bien podrían corresponder a la definición colonial de "pueblo". Más interesante aún, al preguntarles sobre la existencia del cerro Poder de Dios, todos ellos, reunidos en una junta comunal, respondieron señalando con sus dedos al cerro que se encuentra frente a su comunidad, denominado San Gerónimo. Pocos metros al oeste del centro de Pacaja Alta, en dirección a este cerro, existe un terreno anegado que en temporada de lluvias se convierte en una pequeña laguna. Curiosamente, frente al cerro San Gerónimo, dentro de la misma comunidad de Pacaja Alta, a solo $2 \mathrm{~km}$ al sur de su centro y a $1.5 \mathrm{~km}$ de la capital de Santiago de Chaquí, se localiza otro cerro también llamado San Gerónimo. Este contiene en su cumbre una pequeña laguna, cuyo antiguo lecho visible en la imagen satelital, coincide con la superficie de la laguna citada en la fuente. A fin de evitar confusiones, llamaremos a estos cerros San Gerónimo A (el primero) y San Gerónimo B (el segundo). Según cuentan los vecinos mayores de Santiago de Chaquí, el cerro San Gerónimo A -cuyo faldeo sur llega hasta las inmediaciones de ese pueblo- es más benigno y más poderoso que San Gerónimo B. Ambos se enfrentan en las noches de tormenta atacándose con fuertes rayos los que, al igual que la divinidad de Porco, son lanzados con sus hondas. En estas ocasiones San Gerónimo B puede vencer a San Gerónimo A. Otro dato interesante es que para los vecinos entrevistados, ambos cerros guardan fabulosas vetas de plata que serían incluso mucho más ricas que las del cerro de Potosí. Sobre la vetas de San Gerónimo B, algunos ancianos dijeron que éstas están celosamente guardadas para sus descendientes o para otros que vendrán después, puesto que ellos no tienen derecho a explotarlas. De la misma manera, otro vecino contó que cuando los españoles intentaron explotar las vetas de San Gerónimo A, el "tío" se les apareció y les dijo que en vano estaban buscando ya que éstas estaban reservadas para aque-

No $38 / 2009$

ESTUdios ATACAMEÑOS

Arqueología y Antropología Surandinas 
llos que vendrían después..$^{19}$ Es importante señalar que sobre el faldeo este del cerro, se encuentran las ruinas de una explotación minera colonial, a diferencia de San Gerónimo B que no muestra evidencias de explotación.

El documento colonial señala que en la mina del cerro Poder de Dios se habría ocultado la huaca del santuario de Porco. Según Platt y colaboradoras (2006: 169), la huaca de Porco eran tres piedras asociadas con la triple identidad de la divinidad del rayo, llamadas: Choquela (Chuqui Illa), Inti Illapa y Catuylla (Catu Illa). El nombre dado por estos españoles a esta huaca fue el de Santa Bárbara (Platt et al.2006:219), una santa relacionada con la trinidad, el rayo y el mundo subterráneo, y que en Europa es la patrona de los mineros, algo coherente si consideramos que la huaca fue ocultada dentro de una mina. ${ }^{20}$ Ahora bien, junto al cerro San Gerónimo A se localizan otras dos cumbres. La que le sigue es llamada San Felipe y la otra, considerablemente menor, San Gabriel. Sobre las cumbres de los cerros San Gerónimo y San Felipe se encuentran dos capillas-santuarios actuales, las cuales son el escenario de intensas actividades rituales vinculadas con los santos, pero sobre todo con San Santiago y Tata Pumpuri (Figuras 10 y 11).A los pies de estos cerros, en el centro de Santiago de Chaquí se localiza la iglesia de San Santiago, que junto con la de Tata Pumpuri (norte de Potosí), son hoy unos de los más poderosos santuarios del sur de Bolivia. Como es sabido, desde muy temprano en la Colonia, los antiguos cultos prehispánicos al rayo se fusionaron con el culto a San Santiago. Significativamente, en gran parte de los Andes, San Gerónimo y San Felipe se juntan con San Santiago para completar una trinidad asociada al rayo que bien podría corresponder a la antigua divinidad prehispánica. El l e de septiembre, día de San Gerónimo, numerosas comunidades rurales de Bolivia, en particu-

\footnotetext{
${ }^{19}$ Es de notar la relación de estos relatos con el mito de descubrimiento del cerro Rico de Potosí.

${ }^{20}$ La hagiografía de Santa Bárbara nos cuenta que la santa tuvo su revelación estando prisionera de su propio padre en una lujosa torre con dos ventanas. Convertida al cristianismo, abre una tercera ventana en la torre representando así la trinidad. Su conversión llevó a la joven a ser humillada, flagelada y ejecutada más tarde por su progenitor. Inmediatamente después de su muerte, éste fue muerto por un rayo. Además de los mineros, Santa Bárbara es patrona de los artilleros. El depósito de pólvora y municiones de los galeones eran llamados santabárbara. La santa es invocada en las zonas rurales de Europa para protegerse de los rayos (Lapparent 1932; Fournée 1978)
}

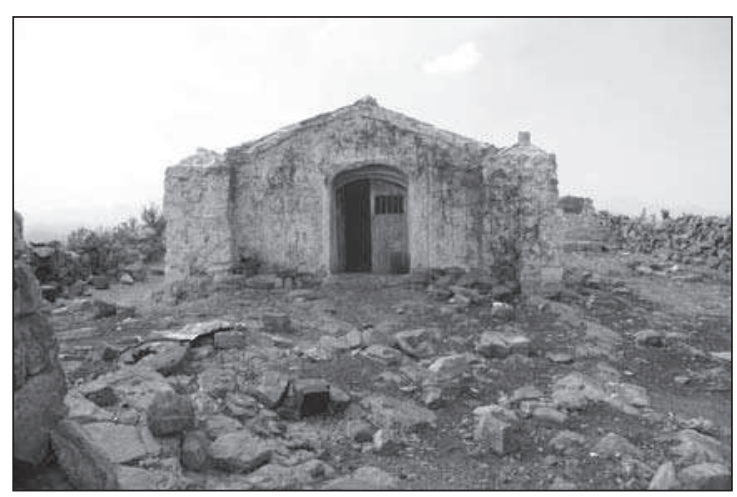

Figura 10. Poder de Dios: Capilla-santuario sobre el cerro San Gerónimo.

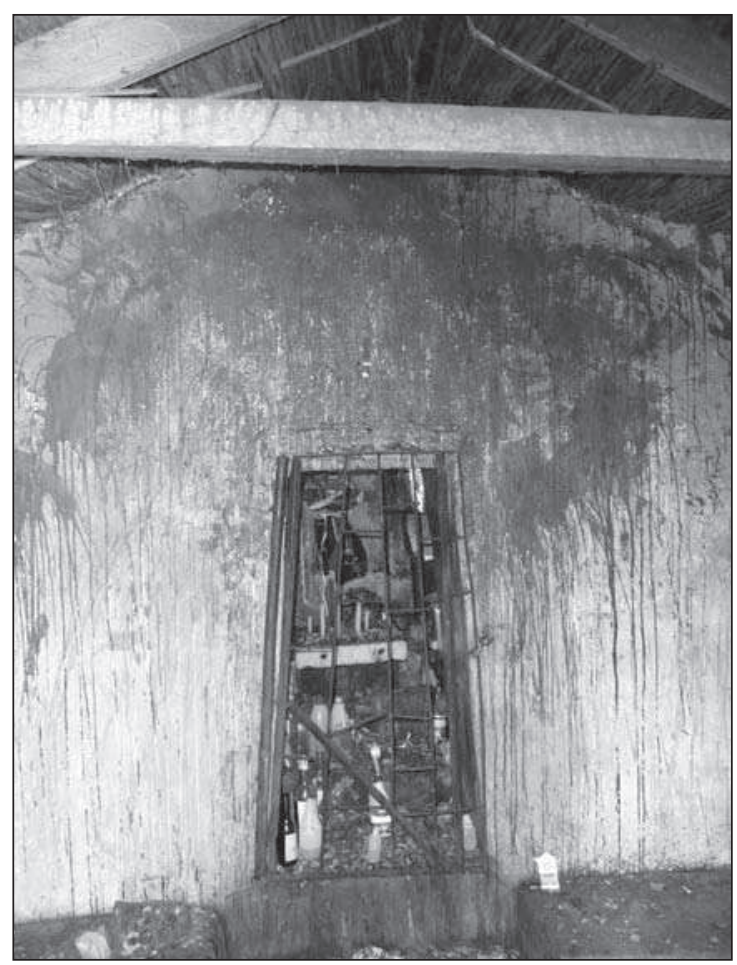

Figura 11. Poder de Dios: Capilla-santuario sobre el cerro San Felipe.

lar los chipayas, celebran estos tres santos y challan las piedras de rayo. Un mito recogido en Chipaya por Cereceda (1993: 249) habla de cuatro divinidades, llamadas "caballeros", maestros del clima que vienen del este, de la lluvia y del rayo que no son otros que San Santiago, San Felipe, San Gerónimo y Yunguyu. ${ }^{21}$

\footnotetext{
${ }^{21}$ Yunguyu, en ocasiones llamado San Yunguyu, es una divinidad relacionada en gran parte del altiplano boliviano con San Santiago
} 
Otros elementos importantes relacionados con el cerro Poder de Dios, la huaca de Porco y el rayo, los encontramos en el interior de la iglesia-santuario de Santiago de Chaquí. En la nave, a pocos metros de la puerta principal de acceso, se encuentra un nicho lateral que conserva tres estatuas modernas: San Felipe a un costado, San Gerónimo en el otro y Santa Bárbara en el centro (Figura 12). Es decir, se trata de una representación que muestra a los dos santos asociados con el rayo en los Andes junto a una santa igualmente vinculada con el rayo, el subsuelo y la minería, pero también con la divinidad prehispánica del rayo, la huaca de Porco ocultada al interior del cerro Poder de Dios. Más adelante, se observa en lo alto un cuadro que muestra la Sagrada Trinidad encarnada en la representación de tres personajes idénticos (Dios, Cristo y el Espíritu Santo), individualizables solo por algunos atributos. Gisbert (2004 [1980]) subraya las asociaciones que pudo tener este tipo de representación con las divinidades tripartitas andinas, en particular Tangatanga, la cual, como Porco, era "...uno en tres y tres en uno...".22 De manera muy sugestiva, Gisbert (2004 [1980]) muestra una representación de la Trinidad en un solo rostro de Cristo tripartito - posiblemente anterior a las representaciones de tres hombres idénticos- bajo el nombre de Poder de Dios. Llamada también "Gran Poder", esta representación se encuentra al centro de la principal festividad religiosa de La Paz (Albó 1986).

Finalmente, es probable que se encuentre relacionado con la importancia de los cerros sagrados de Chaquí, el hecho de que junto a ellos se hayan instalado colonias de mitmaqkunas pakasas y lupaqas. De la misma manera es relevante que el actual pueblo de Santiago de Chaquí, antes la reducción de Xarandilla, haya sido creado al pie del cerro San Gerónimo. El nombre dado a la cabecera no es inocente, Jarandilla (Xarandilla) es el pueblo de Extremadura en donde se encuentra la Casa de los Marqueses de Oropeza, el hogar de quien creó la reducción de Chaquí, el mismo virrey Francisco de Toledo.

En síntesis, a partir del documento transcrito por Platt y colaboradoras (2006), intentamos localizar el ce-

y con el rayo. Es también el nombre de una localidad próxima al lagoTiticaca (Puno, Perú).

${ }^{22}$ Ver también Calancha (1978 [1638-1653]) y Platt y colaboradoras (2006:150).

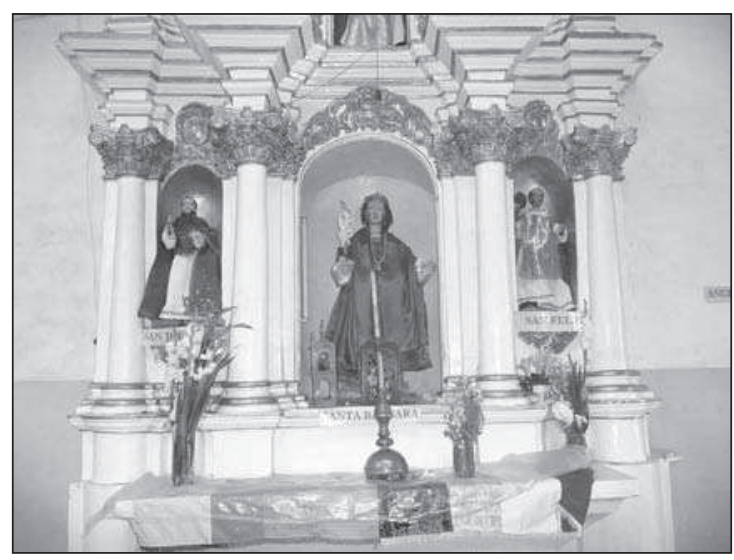

Figura 12. Poder de Dios: Imágenes de San Felipe, Santa Bárbara y San Gerónimo. Iglesia de Santiago de Chaquí.

rro Poder de Dios y rastrear aquellos elementos relacionados con los antiguos cultos que pudieron haber perdurado en el tiempo. El que existan actualmente dos comunidades llamadas Pacaja, dos pueblos llamados Chaquí y dos cerros asociados con lagunas y con el rayo llamados ambos San Gerónimo, dificultó sin duda su identificación. Todo apunta a que el cerro Poder de Dios es el actual cerro San Gerónimo, cuyas faldas llegan hasta la capital de Santiago de Chaquí, siendo el más importante y poderoso de la región. En sus cumbres yacen dos importantes santuarios visitados por los comuneros de Pacaja y de regiones vecinas. Su asociación al rayo, San Felipe, San Santiago y a Santa Bárbara continúa hasta el presente. En cuanto al pueblo viejo de Pacaxa, probablemente consistía en un conjunto habitacional disperso, semejante a las actuales estancias andinas, localizado en territorio de la comunidad de Pacaja Alta. Numerosas piedras partidas por el rayo se encuentran en el centro de la comunidad, al lado de una pequeña capilla colonial en devoción a San Gerónimo y frente al cerro homónimo.

Actualmente, cada 25 de julio, la iglesia-santuario de Chaquí recibe una gran cantidad de devotos de diversas regiones que concurren a celebrar la fiesta de San Santiago. El año 2007 , frente al altar recibieron misa y fueron bendecidas numerosas estatuillas del santo, y aquellas que fueron apadrinadas salieron en procesión dando la vuelta a la plaza del pueblo. Junto a ellas, una roca de aproximadamente $50 \times 25 \times 25 \mathrm{~cm}$, que tiene pintada la representación del santo -y que lo encarna- participó de 


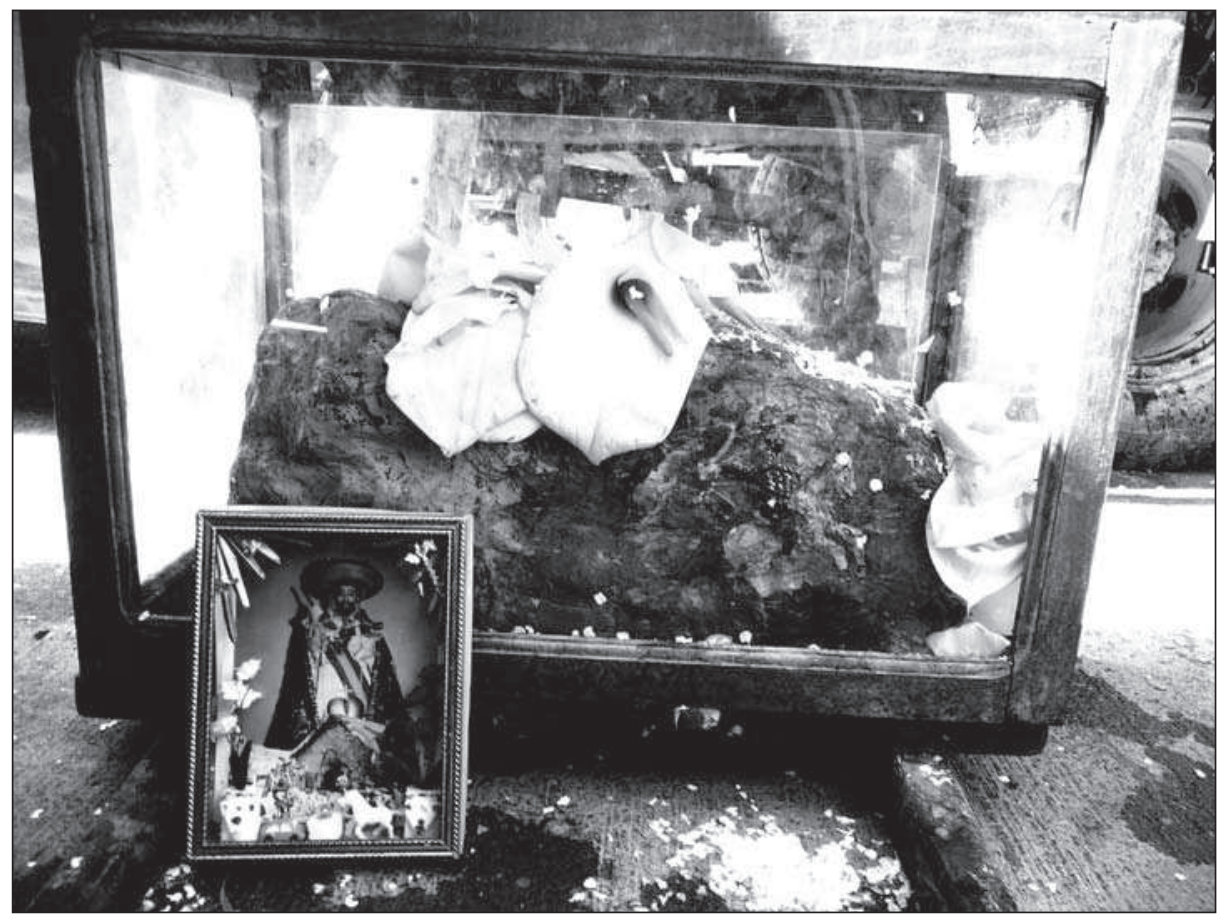

Figura 13. Poder de Dios: Illa con imagen de San Santiago venerada en Chaquí el 25 de julio.

todas las etapas de la fiesta (Figura 13). Por las noches, la iglesia-santuario recibe la visita de especialistas rituales (paqos y jampiris) de toda la región, quienes frente a la torre o detrás de la sacristía realizan sus ritos.

\section{* sobre la cartografía sagrada en los ANDES DEL SUR}

La articulación de diferentes registros (histórico, etnográfico y arqueológico) nos permitió identificar varios santuarios y huaca prehispánicas, y explorar algunos aspectos de los antiguos cultos relacionados con las montañas.

Uno de los datos más interesantes aportados por Calancha (1978 [1638-1653]) al referirse al cerro Quiquijana, es que éste posee el mismo nombre de un cerro de la región de Cusco venerado por los incas. No se trata de un caso aislado. De la misma manera que el Quiquijana, hemos corroborado que muchas altas cumbres y cerros antiguamente sacralizados por los incas en Potosí y Chuquisaca tienen réplicas en otras regiones y se encuentran, en mayor o menor medida, igualmente sacralizados (Tabla 1).
El cerro de Potosí, del cual Guallpa dijo que poseía una huaca y adoratorio en su cumbre, tiene réplicas en Chuquisaca (Potosí), en La Paz (Potosí), en Huanuco (Potosí), en Oruro (Potocsi) y en Arequipa (Potocsi). El Huayna Potosí, posee los suyos en La Paz (Huayna Potosí), en Tomave junto al cerro Mundo (Huayna Potosí) y en la región de Puno (Huayna Potocchi). El cerro Tangatanga, relacionado con la divinidad tripartita del mismo nombre y el santuario del cerro Churuquella (Sucre) tiene sus pares en Puno (Tanca Tanca), en Arequipa (Tanga), en La Paz (Tanga Tanga) y en Oruro (Tanga, Tangani). El cerro Caltama, santuario donde habían varias huaca regionales (Platt et al. 2006), entre ellos el de Porco, posee su réplica en el nevado del mismo nombre situado en la península de Yonza en los Lípez, una cumbre nevada considerada un apu importante. Finalmente, el nevado Illimani de La Paz, tenido igualmente como apu principal desde épocas preincas posee sus réplicas en Potosí y Chuquisaca. Estos son solo algunos ejemplos cercanos a nuestro tema y región de estudio.

En los casos citados, hemos podido ver que la mayoría de los cerros que llevan el mismo nombre no poseen la 


\begin{tabular}{|c|c|c|}
\hline Nombre & Referencias culto & Localización \\
\hline Potosí, Potocchi, Potocsi & $\begin{array}{c}\text { Santuario, adoratorio del sol, } \\
\text { Capac Ique }\end{array}$ & $\begin{array}{c}\text { Potosí (Potosí), Potosí (Chuquisaca), Potosí (Huanuco), } \\
\text { Potosí (La Paz), Potocsi (Arequipa), Potocchi (Puno) }\end{array}$ \\
\hline $\begin{array}{c}\text { Huayna Potosí } \\
\text { Huayna Potochi }\end{array}$ & $\begin{array}{c}\text { Hijo del cerro Rico } \\
\text { Apu, santuario (La Paz) }\end{array}$ & $\begin{array}{c}\text { Huayna Potosí (Potosí), Huayna Potosí (La Paz), Huayna } \\
\text { Potosí (Potosí-Quijarro), Huayna Potocchi (Puno) }\end{array}$ \\
\hline Tanga Tanga & Huaca (tres en uno y uno en tres) & $\begin{array}{c}\text { Tangatanga (Potosí), Tanca Tanca (Puno), Tanga Tanga } \\
\text { (Arequipa) }\end{array}$ \\
\hline Caltama & Huaca de Porco & Caltama (Potosí), Caltama (Yonza, D. Campos) \\
\hline $\begin{array}{c}\text { Quiquijana } \\
\text { Apoquiquixana }\end{array}$ & $\begin{array}{c}\text { Santuario, adoratorio } \\
\text { Gran Señor Quiquixana }\end{array}$ & $\begin{array}{c}\text { Quiquijana (Chuquisaca), Quiquijana (Cusco) } \\
\text { Quiquijana (Apolo, La Paz) }\end{array}$ \\
\hline Choquechampi & Santuario, adoratorio & $\begin{array}{c}\text { Choquechambi (Chuquisaca), Choquechambi (Cusco), } \\
\text { Choquechambi (Arequipa) }\end{array}$ \\
\hline Aquillani & Santuario, adoratorio & Aquillani (Chuquisaca), Aquillani (Cusco) \\
\hline Illimani & Apu, santuario & Illimani (La Paz), Illimani (Potosí), Illimani (Chuquisaca) \\
\hline Sabaya & Tata Sabaya,Apu & Sabaya (Carangas, Oruro), Sabaya (Moquegua) \\
\hline
\end{tabular}

Tabla 1. Correspondencia de cerros con nombres semejantes.

misma morfología: se trata tanto de altas cumbres (sobre los 5000 m.snm), cerros altos (bajo los 5000 m.snm) y serranías accesibles (bajo los $3500 \mathrm{~m} . \mathrm{snm}$ ). Solo algunos cerros llamados Huayna Potosí guardan semejanzas con el cerro que yace a los pies del cerro Rico y que es considerado su hijo. Por otro lado, los nombres de varios de estos cerros sagrados fueron dados por los incas, como es el caso de los cerros Potosí y Quiquijana, mientras que otros, como el Illimani o el Tanga Tanga tienen nombres en lenguas locales (p.e., aymara o puquina). Esto nos lleva a pensar que este ordenamiento forma parte, al igual que los santuarios de altura, de las estrategias de conquista ritual ejecutadas por los incas en su avance territorial.

Varios son los textos coloniales que recogieron mitos en los cuales las huaca y los cerros, lejos de ser inmóviles, se desplazaban, se enfrentaban entre ellos (p.e., el manuscrito de Huarochirí, Taylor 2008), colonizaban territorios y establecían alianzas con sus pares, de la misma manera que lo hicieron los incas. En este sentido, sería interesante abordar desde la arqueología las correspondencias entre estos cerros con igual nombre y la presencia de sitios con semejante cultura material $y$, en el caso de que esto pueda verificarse, evaluar sus temporalidades y sentidos de flujo.
Otra pista interesante que deja ver Calancha (1978 [16381653]) es la conformación de jurisdicciones territoriales asociadas a una huaca o cerro principal y que integraban conjuntos de cerros sagrados. En el caso de Chuquisaca, se trata de un territorio marcado por 12 cerros sacralizados, entre ellos el Apoquiquixana, y que abarca regiones ocupadas antiguamente por qaraqaras y yamparas. Por su parte, la jurisdicción de la huaca de Porco parece corresponder a la cordillera de Los Frailes, un territorio que se extiende desde el borde oriental del salar de Uyuni hasta los valles mesotérmicos de Chuquisaca. Esta jurisdicción estuvo igualmente marcada por un conjunto de cerros sagrados, entre los cuales las fuentes dan los nombres de Potosí, Porco y Caltama. Completando esta información, las prospecciones arqueológicas posibilitaron el registro de santuarios de altura incas sobre otros cerros de esta cordillera, como Cusco (Figura 14), Cosuña y Mundo, y se recogieron informaciones de otros santuarios sobre los cerros Ubina e Inca. Entre estos cerros, localizado al centro de la cordillera de Los Frailes, destaca el cerro Mundo, llamado también Alma Mundo, tanto por la densidad de la evidencia ritual prehispánica registrada en su cumbre, como por continuar siendo hoy en día un apu mayor. Venerado por las poblaciones campesinas e indígenas del sur de Bolivia, su cumbre es el lugar hacia donde se diri- 


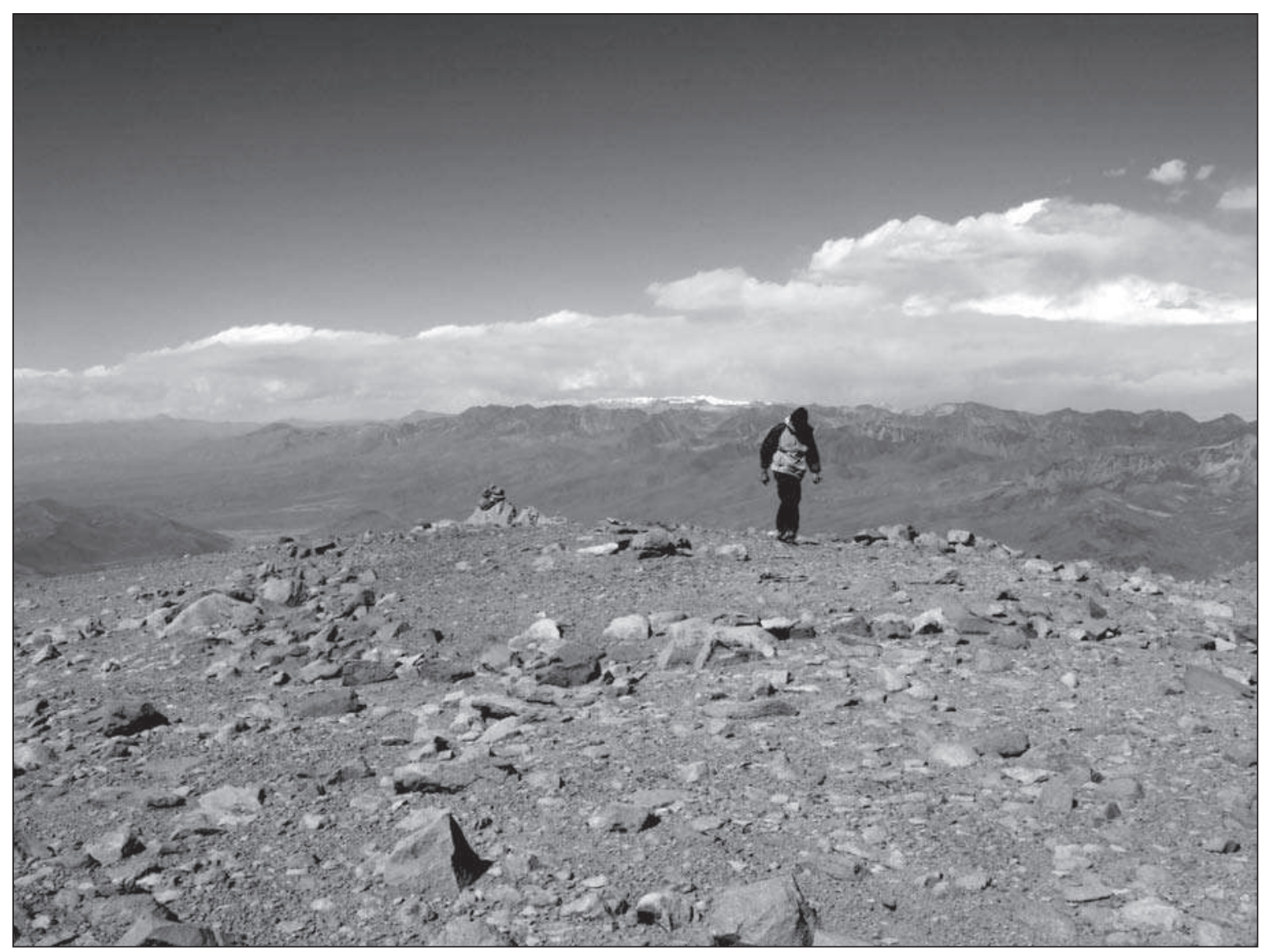

Figura 14. Santuario inca sobre la cumbre del cerro Cusco.

gen todas las almas del mundo en un peregrinaje iniciático que lo vincula directamente con la quebrada de San Bartolomé, y a través de ésta, con el cerro de Potosí y con la antigua jurisdicción de la huaca de Porco. Esta quebrada, llamada antiguamente Mullupunku, constituye desde épocas prehispánicas un importante hito en el paisaje religioso de Potosí. El extirpador jesuita Arriaga (1958 [1621]) da cuenta de cómo el sitio fue objeto de devoción y culto recibiendo peregrinos de regiones alejadas de los Andes (Cruz 2006; Absi y Cruz 2007).

Así vemos que, a diferencia de la experiencia geográfica del mundo occidental, en los Andes prehispánicos numerosas montañas y divinidades fueron integradas en territorios y paisajes fuertemente cargados de significación religiosa y política. El interés volcado por los incas en la adopción, apropiación y resignificación de los cerros y huacas locales da la pauta del importante rol que éstos tuvieron en el reordenamiento simbólico de los territorios incorporados al Tawantinsuyo y en las estrategias de conquista ritual. De esta manera, tal como lo formuló décadas atrás Lefevbre (1976, 1981), los paisajes sociales andinos resultan de, y reflejan, la complejidad de las relaciones sociales, entre ellas la dominación. Con múltiples transformaciones, discontinuidades y continuidades, el rol simbólico de las montañas dentro del paisaje religioso andino se perpetuó en el tiempo, ${ }^{23}$ al punto que en la mayoría de los cerros actualmente sacralizados es posible rastrear su memoria atrás en el tiempo.

"Hay un Cristo andino que tiene por catedrales las montañas”, escribía Diez de Medina (1974), sus palabras van mucho más allá de la simple metáfora.

\footnotetext{
${ }^{23}$ Ver por ejemplo, Favre (1967), G. Martínez (1969, 1989), Berenguer y colaboradores (1984), Bastien (1985), Allen (2002) y Absi (2003).
} 
Agradecimientos Muchas son las personas que me ayudaron a construir esta reflexión. Tristán Platt y Pablo Quisbert aportaron sus conocimientos en un intenso debate del cual surgieron muchas pistas. Pablo Quisbert participó en las prospecciones a los cerros Poder de Dios y Quiquijana, compartiendo los avatares de la investigación de campo. Verónica Cereceda, Théresse BouysseCassagne, Axel Nielsen, Isabelle Daillant, Pascale Absi y los dos evaluadores anónimos se prestaron a la lectura de una versión preliminar de este artículo y lo enriquecieron sustancialmente con sus comentarios. Ana María Presta me proporcionó información sobre la antigua reducción de Chaquí. Finalmente, Crispín Ventura nos acompañó en las ascenciones de los cerros Cusco, Mundo, Turqui y Kari Kari. A todos ellos mi profundo agradecimiento.

\section{* Referencias citadas}

ABSI, P., 2003. Les ministres du diable. Le travail et ses représentations dans les mines de Potosí. Editions L'Harmattan, París.

ABSI, P.y P. CRUZ, 2007. La porte de la waka de Potosi s'est ouverte à l'enfer. La quebrada de San Bartolomé. Journal de la Société des Américanistes 93 (2): 51-86.

ACOSTA, J., DE, 1979 [1550]. Historia natural y moral de las Indias. Fondo de Cultura Económica, México D.F.

ALBÓ, X., 1986. Los señores del Gran Poder. Centro de Teología Popular, La Paz.

ALBORNOZ, C. DE, 1989 [1572]. Fábulas y ritos de los incas, H. Urbano y P. Duviols (Eds.). Crónicas de América 48, Historia 16, Madrid.

ALLEN, C., 2002. The hold life has: Coca and cultural identity in an Andean community. Smithsonian Institution Press, Washington D.C.

ÁLVAREZ, B., 1998 [1588]. De las costumbres y conversión de los indios del Perú: Memorial a Felipe II. Ediciones Polifemo, Madrid.

ARRIAGA, J. DE, 1958 [1621]. Extirpación de la idolatría en el Perú. Biblioteca de Autores Españoles 209. Editorial Atlas, Madrid.

ARZÁNS DE ORZÚA y VELA, B., 1965 [1737]. Historia de la Villa Imperial de Potosí, L. Hanke y G. Mendoza (Eds.). Brown University Press, Providence, Rhode Island.

BASTIEN, J., 1985. Mountain of the condor:Metaphor and ritual in an Andean ayllu. Waveland Press, Long Grove.

BENINO, N. DE, 1965 [1573]. Relación muy particular del cerro y minas de Potosí y de su calidad y labores. En Relaciones geográficas de Indias vol. 2, M. Jiménez de la Espada (Comp.), pp. 362-371. Biblioteca de Autores Españoles, Madrid.
BEORCHIA, A., 1985. El enigma de los santuarios indígenas de alta montaña. Revista del Centro de Investigaciones Arqueológicas de Alta Montaña (CIADAM) 5:410.

BERENGUER, J., C. ALDUNATE y V. CASTRO, 1984. Orientación orográfica de las chullpa en Likan: La importancia de los cerros en la fase Toconce. En Simposio de culturas atacameñas. $44^{\circ}$ Congreso Internacional de Americanistas, B. Bittman (Ed.), pp. 175-220. Universidad del Norte, Antofagasta.

BERTONIO, L., 1984 [1612]. Vocabulario de lengua aymara. Ceres, La Paz.

BOUYSSE-CASSAGNE, T., 1993. El rayo que no cesa. D'un dieu pukina à un dieu inca. En Religions des Andes et langues indigènes: Equateur-Pérou-Bolivie avant et après la conquête espagnole. Actes du III Colloque d'Études Andines, pp. 163-180. Université de Provence, Centre Aixois de Recherches Latino-Américaines (CARLAM), Aix-en-Provence.

2004. El sol de adentro: Huacas y santos en las minas de Charcas y en el lago Titicaca (siglos XV a XVII). Boletín de Arqueología PUCP 8: 59-97.

2008. Minas del sol, del Inka, y de la gente. Potosí en el contexto de la minería prehispana. En Minas y metalurgias en los Andes del Sur, entre la época prehispánica y el siglo XVII, P. Cruz y J. Vacher (Eds.), pp. 278-301. Instituto Francés de Estudios Andinos e Institut de Recherche pour le Développement (IRD), Sucre.

CALANCHA, A. DE, 1978 [1638-1653]. Corónica moralizadora de la Orden de San Agustín en el Perú, I. Prado Pastor (Ed.). Universidad Nacional Mayor de San Marcos, Lima.

CAPOCHE, L., 1959 [1585]. Relación general de la Villa Imperial de Potosí. Biblioteca de Autores Españoles, Madrid. 
CELESTINO, O., 1997. Transformaciones religiosas en los Andes peruanos. Ciclos míticos y rituales. Gazeta de Antropología 13: 59-72.

CENTRO DE ECOLOGÍA Y PUEBLOS ANDINOS (CEPA), 2003. Cuentos andinos de montaña. Latinas Editores, Oruro.

CERECEDA, V., 1993. Cette étendue entre l'Altiplano et la mer. Un mythe Chipaya hors texte. En Mémoire de la tradition, A. Becqelin y A. Molinié (Eds.), pp. 227-284. Sociéte d'Ethnologie, Nanterre.

CERUTI, C., 1999. Cumbres sagradas del Noroeste Argentino: Avances en arqueología de alta montaña y etnoarqueología de santuarios de altura andina. EUDEBA, Buenos Aires.

CIEZA DE LEÓN, P., 1988 [1553]. Crónica del Perú. Editorial Peisa, Lima.

CRUZ, P., 2006. Mundos permeables y espacios peligrosos. Consideraciones acerca de punkus y qaqas en el paisaje altoandino de Potosí, Bolivia. Boletín del Museo Chileno de Arte Precolombino 11 (2):35-50.

2007. Qaraqara e incas. El rostro indígena de Potosí. Estrategias de poder y supervivencia durante los siglos XV-XVI. Chachapuma 2: $29-40$

CRUZ, P. y P. ABSI, 2008. Cerros ardientes y huayras calladas. Potosí antes y durante el contacto. En Minas y metalurgias en los Andes del Sur, entre la época prehispánica y el siglo XVII, P. Cruz y J. Vacher (Eds.), pp. 91-121. Instituto Francés de Estudios Andinos e Institut de Recherche pour le Développement (IRD), Sucre.

CRUZ, P., P. ABSI y S. FIDEL, 2005. ¿Y donde estaban los indios? Potosí antes de la llegada de los españoles. Anuario del Archivo y Biblioteca Nacionales de Bolivia 11: 52-75.

DIEZ DE MEDINA, F., 1974. Nayjama: Introduccion a la mitologia andina. Paraninfo, Madrid.

DUVIOLS, P., 1976. La capacocha.Allpanchis 9: 11-57.

ESPINOZA, W., 1969. El memorial de Charcas: Crónica inédita de 1582. Universidad Nacional de Educación, Lima.

ESTENSSORO, J. C., 2003. Del paganismo a la santidad. La incorporación de los indios del Perú al catolicismo 1532-1750. Travaux de l'Institut Français d'Études Andines 156.

FAVRE, H., 1967. Tayta wamani. Le culte des montagnes dans le centre sud des Andes péruviennes. Publications des Annales de la Faculté des Lettres Aix-en-Provence 61: 121-140.

FOURNÉE, J., 1978. Le culte populaire et l'iconographie de Sainte
Barbe en Normandie. Parlers et Traditions Populaires de Normandie $\mathrm{X}(40)$.

FUENTE SANCT ANGEL, R. DE LA, 1965 [1572]. Relación del cerro de Potosí y su descubrimiento. En Relaciones geográficas de Indias vol. 185, M. Jiménez de la Espada (Comp.), pp. 357-361. Biblioteca de Autores Españoles, Madrid.

GISBERT, T., 2004 [1980]. Iconografía y mitos indigenas en el arte. Editorial Gisbert y Cía., La Paz.

GUAMAN POMA DE AYALA, F., 1989 [1615]. Nueva coronica y buen gobierno. Institut d'Ethnologie (edición facsimilar), París.

LAPPARENT, COMTE DE, 1932. Sainte Barbe conjuratrice de la foudre. Revue de Folklore Français et Colonial 3: 213-223.

LEFEBVRE, H., 1976. Espacio y política. Ediciones Península, Barcelona. 1981. La production de l'espace. Editions Antrophos, París.

MARTÍNEZ, G., 1969. Los dioses de los cerros en los Andes. Journal de la Société des Américanistes LXIX: 85-115. 1989. Espacio y pensamiento. Editorial Hisbol, La Paz.

MARTÍNEZ, J. L., 2003. Practiques discursives coloniales d'identité. Le cas des Lipes au XVIe siècle. Tesis de Doctorado. Ecole des Hautes Études en Sciences Sociales, París.

MATIENZO, J. DE, 1967 [1567]. Gobierno del Perú. Travaux de l'Institut Français d'Études Andines, vol. 11.

NIELSEN, A. y W. WALKER, 2000. Conquista ritual y dominación política en el Tawantinsuyo: El caso de Los Amarillos (Jujuy, Argentina). En Sed non satiata: Teoría social en la arqueología latinoamericana contemporánea, A. Zarankin y F. Acuto (Eds.), pp. 153-169. Ediciones del Tridente, Buenos Aires.

OSSIO, J. (Ed.), 2004. Códice Murúa: Historia y genealogía de los reyes incas del Perú de sus hechos, costumbres, trajes y manera de gobierno, por fray Martín de Murúa (edición facsimilar). Testimonio Compañía Editorial, Madrid.

PÄRSSINEN, M., 2005. Caquiaviri y la provincia Pacasa: Desde el Alto Formativo hasta la conquista española. Universidad Mayor de San Andrés, Colegio Nacional de Historiadores de Bolivia, Editorial Cima, La Paz.

PLATT, T. y P. QUISBERT, 2008. Sobre las huellas del silencio: Potosí, los incas y el virrey Francisco de Toledo (siglo XVI). En Minas y metalurgias en los Andes del Sur, entre la época prehispánica y el siglo XVII, P. Cruz yJ.Vacher (Eds.), pp. 231-277. Instituto Francés de Estudios Andinos e Institut de Recherche pour le Développement (IRD), Sucre. 


\section{Pablo Cruz}

PLATT, T., T. BOUYSSE-CASSAGNE y O. HARRIS, 2006. Qaraqara-charka. Mallku, Inca y Rey en la provincia de Charcas (siglos XV$X V I I)$. Historia antropológica de una confederación aymara. Instituto Francés de Estudios Andinos, Plural, University of St. Andrews, University of London, Inter American Foundation y Fundación Cultural del Banco Central de Bolivia, La Paz.

RAFFINO, R., 1993. Inca: Arqueología, historia y urbanismo del altiplano andino. Corregidor, Buenos Aires.

RAMOS GAVILÁN, A., 1976 [1621]. Historia de Nuestra Señora de Copacabana. Academia Boliviana de Historia, La Paz.

REINHARD, J., 1983. Las montañas sagradas: Un estudio etnoarqueológico de ruinas en las altas cumbres andinas. Cuadernos de Historia 3: 27-62.
TAYLOR, G., 2008. Ritos y tradiciones de Huarochirí. Travaux de l'Institut Français d'Études Andines 260 / Historia andina 36.

VALDIVIA, P., 1960 [1550].A sus apoderados en la Corte. Biblioteca de Autores Españoles, Madrid.

VAN BUREN, M. y B. MILLS, 2005. Huayrachinas and tocochimbos: Traditional smelting technology of the Southern Andes. Latin American Antiquity 16 (1):3-25.

VITRY, C., 1999. Geografía sagrada: Un recorrido toponímico por las montañas de Salta.Miradas 19. 